\title{
B-25 Corrosion Evaluation Summary Report (U)
}

Kerry A. Dunn

Savannah River Technology Center

Strategic Materials Technology Department

Materials Technology Section

Publication Date: January 2002

Prepared by:

Westinghouse Savannah River Company

Savannah River Site

Aiken, SC 29808
DOES NOT CONTAIN

UNCLASSIFIED CONTROLLED

NUCLEAR INFORMATION

ADC \&

Reviewing Official:

Date:

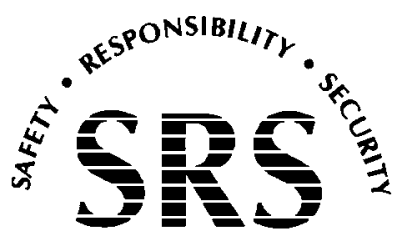

SAVANNAH RIVER SITE

Prepared for the U.S. Department of Energy Under

Contract Number DE-AC09-96SR18500 
This document was prepared in conjunction with work accomplished under Contract No. DE-AC09-96SR18500 with the U.S. Department of Energy

\section{DISCLAIMER}

This report was prepared as an account of work sponsored by an agency of the United States Government. Neither the United States Government nor any agency thereof, nor any of their employees, makes any warranty, express or implied, or assumes any legal liability or responsibility for the accuracy, completeness, or usefulness of any information, apparatus, product or process disclosed, or represents that its use would not infringe privately owned rights. Reference herein to any specific commercial product, process or service by trade name, trademark, manufacturer, or otherwise does not necessarily constitute or imply its endorsement, recommendation, or favoring by the United States Government or any agency thereof. The views and opinions of authors expressed herein do not necessarily state or reflect those of the United States Government or any agency thereof.

This report has been reproduced directly from the best available copy.

Available for sale to the public, in paper, from U.S. Department of Commerce, National Technical Information Service, 5285 Port Royal Road, Springfield, VA 22161

phone: (800) 553-6847

fax: (703) 605-6900

email: orders@ntis.fedworld.gov

online ordering: http://www.ntis.gov/support/index.html

Available electronically at http://www.osti.gov/bridge

Available for processing fee to U.S. Department of Energy and its contractors, in paper, from: U.S. Department of Energy, Office of Scientific and Technical Information, P.O. Box 62, Oak Ridge, TN 37831-0062, phone: (865) 576-8401, fax: (865) 576-5728, email: reports@adonis.osti.gov 


\section{Task Leader: K. A. Dunn}

APPROVALS:

K. A. Dunn

Date

Task Leader

R. L. Sindelar

Date

Manager MaterialsApplications \& Process Technology, Technical Reviewer

W. E. Jones

Date

Subsurface Contaminants Focus Area Customer

G. T. Chandler

Date

Manager Materials Performance \& Corrosion Technology Group 
WSRC-TR-2001-00587

\section{$\underline{\text { Summary }}$}

A destructive examination of a B-25 waste storage container that was buried in a shallow nonradiological land burial facility for approximately 8 years showed that pitting was the most prevalent form of corrosion and suggested that continued burial would result in through-wall pits after 30 years. This result suggests that through wall pits will provide a path for water flow into and out of similar B-25 containers after approximately 30 years of burial. Pitting was the most severe on the exterior of the lid. However, the lid had collapsed into the container, probably because the soil loading exceeded the support capacity of the lid. This observation demonstrates that lid strength is a significant factor when assessing structural integrity of the B-25 containers. The lid had collapse had allowed the container to fill with soil and water. A review of procurement specifications for the B-25 containers suggest that the container examined in this work was purchased from an earlier version of the B-25 container procurement specification.

\section{$\underline{\text { Introduction }}$}

The material condition and integrity of a B- 25 waste storage container that had been buried in a shallow non-radiological land burial facility for approximately 8 years was evaluated. The evaluation was supported by the Subsurface Contaminants Focus Area (SCFA) as part of the "Long-Term Waste Stabilization Design for Long-Term Cover Systems", as described in TTP SR11SS29. The goal of this evaluation was to assess the effect of burial on the integrity of a B25 container and provide data for an emerging generic risk and cost based design methodology for the evaluation and selection of physical stabilization options for long-term cover systems. The B-25 container examined in this investigation was part of a dynamic compaction study prior to being buried in 1993. The structural integrity of the box itself was minimally affected by the dynamic compaction study and the box was, therefore, chosen as a test container to be buried in 1993.

The design of the B-25 container has changed slightly over the years. An earlier version of a typical B-25 design indicates 14-gauge (nominal thickness of 0.0747") low carbon hot rolled steel [1]. The box was approximately $3.9 \mathrm{ft}$. wide X $4.3 \mathrm{ft}$. high, X $6 \mathrm{ft}$. long and was able to contain $4620 \mathrm{lbs}$. According to the current procurement specification [2], B-25 waste containers are constructed of 12-gauge (nominal thickness of 0.1094") carbon steel with a volume of $90 \mathrm{ft}^{3}$. The material specified is ASTM A-569-93, carbon (0.15\%) hot-rolled, sheet and strip, commercial quality steel. Each B-25 waste box shall be capable of holding 6,000 lbs of solid low level radioactive waste with not more than one percent liquid by weight. A minimum dry film thickness of 0.002 inches is required for a primer coat on both the interior and exterior surfaces of all boxes. An exterior alkyd enamel coat, either yellow or gray, is required to be 0.00125 inches thick.

\section{B-25 Excavation and Initial Examination}

Excavation of the B-25 by Construction personnel began in the morning of May 2, 2001. The B25 was uncovered by late afternoon and it was apparent that the lid cover was distorted and slumped into the container, Figure 1. The soil around the B-25 was very moist and both soil and water had accumulated inside the container. The void spaces between the original contents of 
the B-25 had filled with a combination of soil and water, Figure 2. Water flowed from the container when its contents were dumped while some of the moist soil adhered to the container contents and walls. Samples of the adhering soil and from regions near the B-25 burial site were bagged for shipment to an offsite vendor for analyses of soil $\mathrm{pH}$, moisture content, electrical resistivity, and chloride and sulfate concentrations, Table I. Field measurements of the soil adjacent to the $\mathrm{B}-25$ showed a $\mathrm{pH}$ of approximately 5.4 and a temperature of about $64.4^{\circ} \mathrm{F}$, Table II. Under these conditions non-painted, low carbon steel would be expected to experience at least 0.010 inches per year of corrosion loss. However, the majority of the B-25 was protected from corrosion by the "painted" film, thus little to no corrosion was visually noted in the painted areas. Localized corrosion and pitting was observed in regions where the protective coating was breached.

Table I Soil Measurements from Law Engineering and Environmental Services, Inc.

\begin{tabular}{|l|l|}
\hline Parameter & Measurement Data \\
\hline Specific Gravity & 2.67 \\
\hline Moisture Content as Received & $1.9 \%$ \\
\hline Resistivity as Received & $5.8 \times 10^{6} \mathrm{ohm}-\mathrm{cm}$ \\
\hline Resistivity Minimum & $3.0 \times 10^{4} \mathrm{ohm}-\mathrm{cm}$ \\
\hline $\mathrm{pH}$ & 4.57 \\
\hline Sulfate Ion & $<100 \mathrm{mg} / \mathrm{kg}$ \\
\hline Chloride Ion & $<21 \mathrm{mg} / \mathrm{kg}$ \\
\hline
\end{tabular}

The soil samples were reported to contain about $2 \%$ moisture, have a specific gravity of about 2.67 , contain minimal chlorides and sulfates and be very conductive, Table I. Based on values obtained for previous wet soil samples, the moisture content is questionable and probably should be about $20 \%$ [3]. The $\mathrm{pH}$ of the packaged soil was about 4.6. The difference between the $\mathrm{pH}$ of the packaged soil and that of the soil adjacent to the B-25 wall, Table II, could be attributed to a slight $\mathrm{pH}$ increase caused by minor corrosion of the container wall.

Table II On-Site pH and Temperature Measurements

\begin{tabular}{|c|c|c|c|}
\hline Measurement & $\mathbf{p H}$ & Temperature & Notes (5/2/01, 3:00 PM) \\
\hline 1 & 5.3 & $64.7^{\circ} \mathrm{F}$ & Adjacent to B-25 \\
\hline 2 & 5.4 & $64.4^{\circ} \mathrm{F}$ & Adjacent to B-25 \\
\hline 3 & 5.4 & $64.4^{\circ} \mathrm{F}$ & Adjacent to B-25 \\
\hline 4 & 5.7 & $64.4^{\circ} \mathrm{F}$ & Adjacent to B-25 \\
\hline 5 & 5.4 & $64.6^{\circ} \mathrm{F}$ & Adjacent to B-25 \\
\hline 6 & 5.3 & $64.5^{\circ} \mathrm{F}$ & Adjacent to B-25 \\
\hline
\end{tabular}

Samples of the water inside the B-25 were nearly neutral with chemistries typical of shallow ground water exposed to iron, wood and other container constituents that, when in contact with water, may cause a slight increase in $\mathrm{pH}$, Table III. Additionally, the soil samples showed no 
WSRC-TR-2001-00587

appreciable differences in iron content in the soil adjacent to the B-25 and a short distance from the B-25, Table IV. The lack of significant increases in the quantities of iron in the soil adjacent to the B-25 is consistent with the absence of significant general corrosion on the canister exterior.

Table III Measurements Made by SRTC Analytical Development Section, pH and Inductively Coupled Plasma (ICP).

NOTE: Water sample treated with HNO3 to ensure iron is in free solution rather than bound up on surface of bottle.

\begin{tabular}{|l|c|c|}
\hline Measurement & $\mathbf{H}_{\mathbf{2}} \mathbf{O}$ Sample Untreated & $\mathbf{H}_{\mathbf{2}} \mathbf{O}$ Sample Treated with $\mathbf{H N O}_{\mathbf{3}}$ \\
\hline $\boldsymbol{p H}$ & 6.5 & $<1$ \\
\hline $\boldsymbol{A l}(\boldsymbol{m g} / \mathbf{L})$ & $<0.048$ & 0.35 \\
\hline $\boldsymbol{C a}(\mathbf{m g} \boldsymbol{L})$ & 37.1 & 37.4 \\
\hline $\boldsymbol{F e}(\boldsymbol{m g} / \mathbf{L})$ & $<0.0088$ & 149.0 \\
\hline $\boldsymbol{M g}(\mathbf{m} / \mathbf{L})$ & 15.0 & 15.0 \\
\hline
\end{tabular}

Table IV Soil sample measurements made by X-Ray Fluorescence (XRF). Values are given in weight percent.

\begin{tabular}{|l|l|l|l|l|l|l|l|l|l|l|}
\hline Sample & $\mathbf{S i O}_{\mathbf{2}}$ & $\mathbf{A l}_{\mathbf{2}} \mathbf{O}_{\mathbf{3}}$ & $\mathbf{F e}_{\mathbf{2}} \mathbf{O}_{\mathbf{3}}$ & $\mathbf{M n O}$ & $\mathbf{M g O}$ & $\mathbf{C a O}$ & $\mathbf{N a}_{\mathbf{2}} \mathbf{O}$ & $\mathbf{K}_{\mathbf{2}} \mathbf{O}$ & $\mathbf{T i O}_{\mathbf{2}}$ & $\mathbf{P}_{\mathbf{2}} \mathbf{O}_{\mathbf{5}}$ \\
\hline 162967 & 77.22 & 12.73 & 3.43 & 0.01 & 0.07 & 0.05 & 0.04 & 0.15 & 0.77 & 0.05 \\
\hline 162968 & 75.17 & 13.93 & 3.73 & 0.01 & 0.07 & 0.09 & 0.06 & 0.14 & 0.81 & 0.05 \\
\hline 162997 & 75.23 & 14.12 & 3.55 & 0.07 & 0.06 & 0.07 & 0.06 & 0.16 & 0.80 & 0.05 \\
\hline
\end{tabular}

NOTE: Soil sample 162967 obtained approximately one foot away from top of B-25 container. Soil sample 162968 was touching B-25 at top of container.

Soil sample 162997 was adjacent to the bottom of the B-25 container.

The B-25 containers are designed with three support sections welded to the bottom of each container to allow for lifting and moving from one location to another. Additionally, the handles on the lid of each B-25 container are positioned to be between the support sections when the containers are stacked one on top of another. During the initial field examination straps were inserted beneath the support sections to form a sling for lifting the upper B-25 container from the burial location. The lift sling was attached to a crane and began lifting the B-25 container out of the burial ditch. Inadvertently, the straps were inserted through a handle on the lid of the lower B-25 container. Therefore, the crane also lifted the lid of the lower B-25 container. The lifting process was reversed when this was observed and the B-25 containers were returned to their original position in order to re-position the lifting straps. Once the lifting straps were repositioned the upper B-25 container was removed from the burial ditch and turned on its side to empty most of the water and dirt from the container, Figure 2. The contents of the lower B-25 container were then examined since its lid had already been lifted during the excavation. The lower B-25 container was filled with wood as simulated waste. Additionally, there were approximately two feet of stagnant water inside the container even though the lid of this lower B-25 container had not caved into the storage volume, Figure 3. Apparently, water leaked in through the lid to box closure seam suggesting that the lid was not leak tight on the container. The water exhibited an obvious "landfill" odor, suggesting an anoxic environment within the B- 
WSRC-TR-2001-00587

25 container. The lid was closed and the container remained in the ground for future examinations.

\section{Laboratory Examination and Analysis}

The excavated B-25 container was transferred to a laboratory in 773-A for further detailed examination including destructive metallurgical analysis. Corrosion product was not evident on the exterior side walls of the B-25 container, Figure 4. The alkyd enamel was generally intact over the majority of the exterior surface, Figure 5. However, in spite of the lack of obvious corrosion, blistering of the alkyd enamel was prevalent over most of the exterior surface of the container and many of the enamel blisters were cracked, Figure 6. The cracks exposed the underlying material to the environment. Alkyds in general are oil-based or oil-modified polyester resin coatings that cure by oxidation. (Curing by oxidation contrasts epoxy coatings which cure because of reactions between the materials already in the epoxy mixture.) Therefore, alkyd coatings are generally only specified for corrosion protection during above ground service and are not intended to provide any protection during burial. Alkyds have high permeability to moisture and are not resistant to either acidic or alkaline conditions. Moisture permeation through the coating leads to corrosion of the underlying metal. The corrosion process in slightly acidic electrolytes is metal plus water going to metal oxide plus hydrogen. The corrosionproduced hydrogen is trapped beneath the alkyd film and eventually leads to blistering and even delamination of the coating.

Wood pieces placed in the box as simulated waste showed little signs of degradation, Figure 4. However the evaluation of the wood was limited to a visual inspection.

The majority of blisters on the vertical walls of the B-25 were approximately $1 / 8$ " in diameter, although some larger blisters were evident, Figure 7. Growth of the blisters is due to cathodic delamination around the edges of the blister. In most cases when an intact blister was scraped away, the primer appeared to be securely adhered to the metal surface. The lack of blistering in the primer, Figure 7 (c), suggests that the primer is permeable to both moisture and hydrogen. However, there were areas where both the enamel and the primer degraded. In those areas an oxide buildup was observed, Figure 8. This oxide was black, which is indicative of $\mathrm{Fe}_{3} \mathrm{O}_{4}$ rather than $\mathrm{Fe}_{2} \mathrm{O}_{3}$, which is the typical rust color. Generally, $\mathrm{Fe}_{3} \mathrm{O}_{4}$ will form as a corrosion product when the oxygen content is restricted. Any oxygen involved in the corrosion reaction that was not from the water itself had to permeate both the alkyd film and the primer and was therefore permeation limited.

This data suggests that the steps involved in film/container degradation of an initially undamaged system include:

a) Water permeation through the alkyd coating,

b) Water permeation through the primer coating,

c) A metal-water reaction to produce $\mathrm{Fe}_{3} \mathrm{O}_{4}$ and $\mathrm{H}_{2}$,

d) Hydrogen permeation through the primer and accumulation at the alkyd/primer interface,

e) $\mathrm{Fe}_{3} \mathrm{O}_{4}$ accumulation at the primer/metal interface,

f) Blistering of the alkyd coating,

g) Blister growth, cracking of the alkyd coating and $\mathrm{Fe}_{3} \mathrm{O}_{4}$ induced destruction of the primer 
h) Exposure of the underlying metal to the external environment, and

i) Pitting of the exposed area.

Minor pitting on the exterior of the container was observed. The interior of the container sides did not show any evidence of corrosion product accumulation, Figure 9, although flakes of the black primer were easy to peel from large areas, approximately $20 \mathrm{in}^{2}$, Figure 9 (c). Examination of the outside of the container bottom showed large areas of general corrosion, apparently associated with areas where a forklift truck damaged the protective alkyd film during container handling, Figure 10.

The B-25 container was structurally sound even though the corners and edges had been slightly crushed due to previous compacting, Figure 4. One corner in the bottom of the box had a through wall leak path that allowed a small amount of water to leak from the container while it was stored in the laboratory.

The lid of the B-25 was caved into the box and a large amount of soil closely adhered to the external surface, Figure 11. The lid was transported to the laboratory in 773-A with the soil intact so that the regions of contact between the lid and the soil could be examined during the soil removal process, Figure 12. The contained contact surfaces of soil samples removed from the lid had replica imprint of the pits that had developed in the lid, Figure 13. These replica imprints demonstrated the degree of contact between the soil and the lid. Macroscopic pits associated with the replica imprints and from regions where the soil had detached prior to the examination were observed on the exterior surface of the lid. The pits varied in size from approximately $1 / 8 "$ in diameter to approximately $1 / 4 "$ in diameter, Figure 14 . In several areas a group of pits had coalesced to form a large area of degradation (approximately 9 in. $^{2}$ ), Figure 15. On the underside of the lid, some areas of primer delamination and material degradation were observed, Figure 16.

\section{Material Parameters and Procurement Specification}

The current procurement specification for a B-25 [2] identifies "ASTM A-569-93, steel, carbon $(0.15 \%)$ hot-rolled, sheet and strip, commercial quality", for the material of construction. That particular ASTM standard has been discontinued and the last issue date for the standard was May 10, 1998. An AISI steel equivalent to ASTM A-569-93 has not been identified, thus satisfaction of the procurement may be difficult unless equivalence is established.

Results from the metallography of the B-25 sections being examined indicate that the nominal wall thickness is close to 0.0775 " which is $20 \%$ less than the minimum required wall thickness in the curent specification [2]. This is, however, consistent with a previous procurement specification [1], which required 14-gauge carbon steel (nominal thickness of 0.0747 "). The current procurement specification requires a 12-gauge carbon steel (nominal thickness of 0.1094 "), a primer thickness of 0.002 " inside and outside the box, and an alkyd enamel thickness of 0.00125 " on the exterior of the box [2].

Additionally, the primer thickness on the excavated B-25 container is approximately half of the primer thickness specified in the current procurement specification and the alkyd enamel thickness is approximately twice the thickness quoted in the current purchase specification, 
Figure 17. If the primer thickness on in-service B-25 containers is only half of the specified thickness then the corrosion protection in these containers is significantly below the implied levels. These findings indicate that differences between B-25 containers may exist and that a complete analysis of the various types of B-25 container is required to ensure the applicability of any assessment of the in-service behavior.

\section{Soil Properties}

The soil around the excavated B-25 was very moist indicating a fair amount of water present at the depth of burial. The type of shallow soil overlying a large part of the site is described as loamy and composed of particles that are clay, silt, and sand [4]. The underlying soils are sandy clays and clayey sands of the upland formation. In this excavation area, residual Kaolin, in powder form, was included in the soil. The Kaolin was originally used in a nearby capping test and comprised less than $5 \%$ of the total soil (by visual estimate). The residual Kaolin in the excavated soil was not well dispersed and clumps of Kaolin, as opposed to the intended homogeneous mixture, were present. The remainder of the soil around the B-25 was primarily sandy clay. The clay is highly plastic and becomes sticky when saturated with water. Such soils shrink and crack on drying, and swell on re-wetting. Soil shrinkage and the associated crack should provide easy percolation pathways to the buried B- 25 containers. The existence of such pathways would explain the water accumulation inside the buried B-25 containers. Additionally, the soil on the B-25 lid had adhered to the alkyd coating. Therefore, when the adherent soil contracts and expands, the protective coating on the B-25 container is cyclically stressed. The repeated stresses should eventually fracture the protective coatings and provide sites for the initiation of degradation. The cyclic stresses may also combine with the already adverse effects of water permeation through the coatings to enhance the container degradation process.

The corrosivity of a soil is related to $\mathrm{pH}$, resistivity, chemistry, texture and drainage. Surprisingly, soil temperature (in temperate climates and non-geothermal areas) seems to have a minimal effect on the corrosion process [5]. The $\mathrm{pH}$ values measured by the two laboratories were slightly different, $(5.3$ to 5.7$)$ vs. (4.5 to 5.0$)$. Soils with $\mathrm{pH}$ values in the first range are defined as a medium acidic to a strongly acidic soil while soils in the second range are defined as strongly acidic soils [5]. However, either range should provide an environment conducive to corrosion of iron, if the resistivity of the soils are low enough for easy electron transfer. Corrosion is an electrochemical process and electron transfer is a necessary prerequisite. Because of this, soil resistivity is the most commonly used parameter for assessing the potential for corrosion in a soil environment. The measured value of soil resistivity $\left(5.8 \times 10^{6} \mathrm{ohm}-\mathrm{cm}\right)$ is consistent with a "very mildly corrosive" classification of soil corrosiveness [6]. This classification is consistent with the corrosion with the excavated B-25 container. Additionally, the concentrations of sulfate and chloride ions are relatively low indicating that the soil chemistry does not strongly lend itself to a corrosive environment. Therefore, these observations suggest that the soil at the B-25 excavation site should be categorized a very mildly corrosive. This classification is consistent with previous findings for soil in this area [7]. As previously stated, moisture measurement reported in Table I is lower than would be expected and field observations, reflectometer and Shelby tube measurements from nearby sampling of similar material and depths, suggest that the moisture content should be 11.4 to 27.0 percent by weight [8]. 
WSRC-TR-2001-00587

\section{$\underline{\text { Metallurgical Analysis }}$}

Structurally, the B-25 container walls were intact with very little evidence of buckling. This observation is consistent with previous studies [9]. One corner of the container which was somewhat crushed was evaluated to determine if the crushing had caused a through wall failure. The corner section was cut from the container and positioned so that it could be filled with water. The water filled section was then monitored and a slow leak was observed. It is likely that a welded corner was the source of the leak; however, further evaluations would be required to confirm this speculation.

Various levels of degradation were observed from the samples sectioned from the walls of the B25 container. Certain areas sectioned exhibited little to no degradation, Figure 17. In these areas, the primer was in tact on the interior and the primer and alkyd enamel were in tact on the exterior. Regions where blistering of the alkyd enamel paint were observed had very shallow pits, Figure 18 while regions where the blister had cracked and flaked off showed deeper pits, Figure 19. Regions where the blister flaked off and an oxide layer had formed showed the deepest pits, Figure 20. These observations are consistent with the various stages of pitting corrosion previously described.

The bottom of the B-25 was intact and had supported the weight of the simulated waste (lumber) and the accumulated water without any signs of buckling. However, the bottom interior had large areas of primer delamination, Figure 21. This delamination is attributed to the permeation of the stagnant, accumulated water to the metal/primer interface and the initiation of corrosion in that region. Corrosion product (iron oxide and hydrogen) generation then destroyed the primer/metal bond and caused the delamination. General corrosion was evident on certain areas of the bottom exterior of the B-25, Figure 22. These regions of general corrosion corresponded to the regions where the lifting prongs of a forklift contacted the container during handling operations, Figure 10. The corrosion from both the outside and the inside of the bottom plate resulted in a reduction of wall thickness by $30 \%$.

The lid deformation was most likely caused by the weight of the soil upon burial of the B-25 container eight years ago [9]. There was no evidence that this deformation, by itself, caused a breach in the coating to exacerbate corrosion. Additionally, one of the upper B-25 lid handles was torn from the container, Figure 23, during the burial process. Corrosion on both the interior (underside) of the lid and the exterior of the lid was present, Figure 24. On the underside of the lid, some areas of primer delamination and material degradation associated with general corrosion, were observed. The exterior of the lid had large areas of pitting and in several areas the pits coalesced in a central location to form a large area of degradation (approximately $9 \mathrm{in}^{2}$ ), Figure 15. Metallographic cross sections of the lid show the presence of general corrosion, individual pits and coalesced pits, Figure 25-26. The soil, being in such close contact with the lid, showed the replica imprint of the pitting corrosion on the lid exterior, Figure 13. Where there was close contact with the soil on the lid, there was no evidence of the alkyd enamel remaining on the lid. The alkyd enamel appeared to have "dissolved" into the soil as a result of the moist environment. 
WSRC-TR-2001-00587

\section{Discussion of Results}

The B-25 container examined in this investigation was part of a dynamic compaction study prior to being buried in 1993 [10]. The structural integrity of the box itself was minimally affected by the dynamic compaction study and the box was, therefore, chosen as a test container to be buried in 1993. It was reported that corrosion of the dynamically compacted containers was greater than that of uncompacted containers following burial. Based on information gathered in the current evaluation, it is expected that blistering of the alkyd enamel, as a result of moisture in the soil, began during the dynamic compaction and burial process. These areas of blistering eventually lead to pitting in the walls of the container, as examined by the eight year burial study.

Pitting was found to be the primary form of corrosion on the B-25 container. Pitting is an intense localized form of corrosion and can be very rapid especially if an occluded cell develops during the pitting process. The presence of chlorides in the surrounding environment may stimulate pit initiation and growth. However, the water extracted from the soil around the excavated B-25 did not indicate unusually high concentrations of $\mathrm{Cl}^{-}$ions suggesting that the pits nucleated in the B-25 container because of local defects and/or weaknesses in the protective coating. These defects may be inherent in the as applied coatings, developed through soil/coating interactions or, as seen by the effects of the forklift, produced during the handling and burial process.

Pits usually grow downward, in the direction of gravity. Therefore, pitting is most commonly observed on the top of a horizontal surface or the bottom of a tank, pipe or container [11]. Additionally, stagnant water provides a greater propensity for pitting corrosion than does flowing water [11]. These relatively general observations of pitting tendencies rationalize why a large amount of pitting was observed on the lid of the B-25 container. The close contact with wet soil could provide the stagnant water source for pit initiation and the lid orientation allows for downward pitting. Additionally, pits on the side-walls were generally smaller in diameter and smaller in depth than those on the lid. However, the influence of gravity on pit initiation and growth is generally attributed to the role of inclusions and debris in the pitting process. In this case, pit initiation is apparently controlled by water permeation through, or degradation of, the coating and gravity should play minimal roles in these processes. Additionally, the low carbon steel used to construct the B-25 container will corrode when in direct contact with slightly acidic water and soil. Thus, when the protective layer was removed to expose the metal surface general corrosion will occur in the exposed area. Because the coating was removed from the bottom of the container prior to burial, this region began to corrode almost immediately and is therefore the most corroded region in the $\mathrm{B}-25$ container.

The calculated corrosion rates for, and times to penetration of, various regions on the B-25 container are shown in Table $\mathrm{V}$. The rates of corrosion given in Table $\mathrm{V}$ are estimated by assuming that corrosion occurred at a constant rate throughout burial. These rates may not represent highly accurate estimates of time to penetration because: 1) pitting can be autocatalytic in nature [11] and 2) pitting rate sometimes follows a power law with the exponent on time less than $1[6,12]$. Therefore, the actual time to observe a through wall pit may be significantly less 
than or greater than that shown in Table V. For purposes of this study, we will characterize the corrosion rate reported as a constant corrosion rate of the B-25 container.

The increased amount of corrosion on the exterior of the B-25 floor where a forklift had scraped the B-25 surface is not unusual because the protective coat was removed and the metal surface was exposed. This corrosion in this area is termed general or uniform corrosion. Uniform corrosion generally occurs at a constant rate if, as is the case for iron in slightly acidic water, the corrosion process does not produce a protective film. Therefore, the rate of general corrosion calculated for the bottom of the B-25 floor may accurately reflect the corrosion rate for a B-25 container buried under similar conditions.

Table V Corrosion Rate for Different Areas on B-25 Container

\begin{tabular}{|c|c|c|c|c|}
\hline $\begin{array}{l}\text { Area On } \\
\text { B-25 }\end{array}$ & $\begin{array}{l}\text { Type of } \\
\text { Corrosion }\end{array}$ & $\begin{array}{l}\text { Corrosion } \\
\text { Rate (mils } \\
\text { per year) }\end{array}$ & $\begin{array}{l}\text { Estimated No. of Years to } \\
\text { Through Wall Pit } \\
* 14 \text {-gauge }-0.075 " \text { thick } \\
* * 12 \text {-gauge }-0.1094 " \\
\text { thick }\end{array}$ & Notes \\
\hline Wall & Pitting & $1.1 \mathrm{mpy}$ & $\begin{array}{l}* 70 \text { years } \\
* * 100 \text { years }\end{array}$ & $\begin{array}{l}\text { This type of pitting } \\
\text { was typical across } \\
\text { most of the side } \\
\text { walls }\end{array}$ \\
\hline Wall & Pitting & $2.7 \mathrm{mpy}$ & $\begin{array}{l}* 29 \text { years } \\
* * 40 \text { years }\end{array}$ & $\begin{array}{l}\text { This was the } \\
\text { deepest pit } \\
\text { observed in a side } \\
\text { wall - not typical }\end{array}$ \\
\hline Lid & $\begin{array}{l}\text { Pitting - } \\
\text { coalesced }\end{array}$ & $2.4 \mathrm{mpy}$ & $\begin{array}{l}* 33 \text { years } \\
* * 46 \text { years }\end{array}$ & $\begin{array}{l}\text { Would expect that } \\
\text { this region would } \\
\text { be first to fail } \\
\text { structurally } \\
\text { because of } \\
\text { coalesced pitting } \\
\text { and close contact } \\
\text { with the soil }\end{array}$ \\
\hline Bottom & $\begin{array}{l}\text { General } \\
\text { corrosion } \\
\text { (outside) and } \\
\text { degradation } \\
\text { (inside) }\end{array}$ & $2.6 \mathrm{mpy}$ & $\begin{array}{l}* 30 \text { years } \\
* * 42 \text { years }\end{array}$ & $\begin{array}{l}\text { Corrosion seen } \\
\text { outside from } \\
\text { forklift operations. } \\
\text { Degradation inside } \\
\text { from primer } \\
\text { delamination, } \\
\text { standing water and } \\
\text { abrasions from } \\
\text { simulated waste }\end{array}$ \\
\hline
\end{tabular}

Anticipated failure scenario 
Several key factors must be considered when assessing the failure scenario(s) for the buried B-25 containers. The two different failure scenarios that are described here include 1) corrosion penetration through the B-25 container walls and 2) structural instability and collapse of a buried B-25 container.

The first failure scenario, corrosion penetration of the B-25 container walls, will likely result from pitting corrosion. Table $\mathrm{V}$ provides corrosion rates for various areas of the B-25 container and the most aggressive rate provided is $2.7 \mathrm{mpy}$. If we assume a constant corrosion rate over time, the container wall will be penetrated by pitting corrosion in 29 years. At that point, the requirement in the current procurement specification for a container to be leak tight will no longer be met which would facilitate the movement of water or humid air into the B-25 container. This leaking of water or humid air constitutes failure, as described in the first scenario above.

The second failure scenario, structural instability and collapse of a buried B-25 container, is more difficult to quantify. The time to reach a condition of a sufficiently thinned container leading to structural instability cannot be accurately estimated from the corrosion evaluation of a single buried container and the structural analysis performed to date. Further evaluations of buried B-25 containers would be necessary to more accurately estimate the time to corrosion induced thinning, thus leading to structural instability and collapse. A structural analysis using data from the current B-25 corrosion evaluation in conjunction with soil properties and other parameters would provide the most accurate assessment of the time to structural instability leading to collapse. Therefore, an estimate of time to achieve structural instability in a buried B25 container will not be given in this report. However, a more thorough discussion of corrosion attack on each portion of the B- 25 container evaluated is provided below.

Lid deformation caused by the weight of the soil upon burial of the B- 25 container eight years ago was observed. There was no evidence that this deformation, by itself, caused a breach in the coating to exacerbate corrosion. The current examination showed that areas on the lid where pits had coalesced to produce a continuous area of degradation through $25 \%$ of the wall included $2 \%$ of the lid. This reduction in wall thickness is primarily outside to inside, however, evidence of inside to outside corrosion was also observed. Total area of the B-25 container lid is $2.1 \mathrm{~m}^{2}$. The corrosion rate for these large areas of degradation is approximately 2.4 mpy and they would likely see through wall corrosion within 33 years. These large areas of through wall corrosion may eventually lead to structural instability of the lid because of the concentrated areas of degradation. Paint blisters, leading to pits, are evenly dispersed across the remainder of the lid surface. Approximately $20 \%$ of the remaining surface contained pits. The corrosion rate of these pits is approximately $1.7 \mathrm{mpy}$ and through wall corrosion will occur in about 46 years. This even distribution of paint blisters is consistent with the remainder of the container walls.

The bottom of the B-25 was intact and had supported the weight of the simulated waste (lumber) and the accumulated water without any signs of buckling. Examination of the container below the one evaluated in this current study revealed approximately two feet of stagnant water despite the observation that the lid appeared to be securely in place. This suggests that all boxes buried in the burial ground will contain stagnant water, regardless of structural damage to the container. Waste products buried inside the B-25 containers may contain materials that will leach out chlorides and fluorides into the water. Pitting corrosion is usually associated with stagnant conditions, especially where chloride and fluoride ions are present, and would therefore be 
expected from the inside to the outside of all boxes buried, as was seen in the container examined. In addition, it is expected that all boxes buried will have comparable corrosion on the outside bottom because of the similar forklift operations. Based on these observations, it is expected that the bottom of all containers buried may degrade at approximately the same rate and will, ultimately, fail at approximately the same time. Total area of the bottom is $2.1 \mathrm{~m}^{2}$. The container examined showed approximately $27 \%$ reduction in wall thickness across approximately $24 \%$ of the bottom side. Corrosion rate in these areas would be 2.6 mpy and through wall corrosion would take approximately 30 years. The remainder of the bottom had a relatively even amount of degradation on the inside with both pitting and general corrosion. Approximately 6\% reduction in the wall thickness across the remainder of the bottom was observed. Corrosion rate in these areas is $0.63 \mathrm{mpy}$ and through wall corrosion will take approximately 125 years.

The vertical walls of the B-25 container would be expected to remain structurally intact longer than the lid or bottom because pitting is more dispersed across the surface and stiffeners have been added to each wall. Therefore, structural instability of a buried B-25 container will not likely occur until the walls collapse. The welded corners also provide additional stability to the walls. Total area of the B-25 container walls is $7.2 \mathrm{~m}^{2}$. Pitting corrosion of the vertical walls of the B-25 container examined showed approximately $13 \%$ reduction in wall thickness across $20 \%$ of the walls. Corrosion rate of the pits in these areas would be $1.3 \mathrm{mpy}$ and through wall pitting corrosion would take approximately 61 years. The remainder of the area $(80 \%)$ is relatively unaffected by pitting corrosion.

\section{Conclusion}

Corrosion assessment of a B-25 container buried for approximately 8 years established that the B-25 container was procured to earlier specifications. Current procurement specifications for the B-25 containers are more conservative with respect to corrosion protection and container degradation. The specification should be changed to reflect the discontinuation of specification ASTM A-569-93 steel.

Corrosion of the lid, vertical walls, and bottom was present in varying degrees. Several areas were not affected at all by corrosion while others lost up to $30 \%$ of the wall thickness. The side walls, in general, were less affected by pitting corrosion than the lid. Pitting corrosion on the side walls was observed from the outside to the inside and the pits were largest where the alkyd enamel and primer had debonded from the surface. Minimal corrosion from the inside to the outside was observed on the side walls. Pits on the exterior lid were largest in diameter and coalesced to form large areas of degradation. General corrosion was evident on the outside bottom of the B-25 due to film removal through repetitive contact with a forklift.

The container degradation observed is consistent with burial in slightly acidic soils. Calculated corrosion rates, assuming a constant corrosion rate, suggest that the walls of similarly buried B25 containers will be penetrated by corrosion within 30 years. However, literature suggests that that the time to penetration could be somewhat less because of the potentially autocatalytic nature of pitting processes, or somewhat more because pitting rate sometimes follows a power law with the exponent on time less than 1. A corrosion analysis of another B-25 buried in 
WSRC-TR-2001-00587

similar soil conditions for a longer period of time will provide additional evidence regarding the mode of pitting corrosion for similar B-25 containers.

In general, the structural soundness of the B-25 was good. Corrosion did not cause a loss of structural capacity following eight years of burial. The lid, however, was severely weakened by the weight of the soil when the container was buried. The buckling of the lid left the inside of the B-25 container open and susceptible to being filled with soil and water. Additionally, even though there is a requirement for a leak tight container, the water accumulation in the second B25 container suggests that this requirement can not met, even if the lid is not buckled.

\section{Acknowledgements}

The author wishes to acknowledge Dr. M. R. Louthan, Jr. for his insight in the editing of this report and also, E. R. LaBord and B. Dinkins for their assistance in the field and in the laboratory.

\section{$\underline{\text { References }}$}

[1] Dames \& Moore, Subsidence Study of B-25 Metal Containers at the Mixed Waste Management Facility, DMSRP-97, March 4, 1987

[2] Low Level Waste B-12 and B-25 Box Specification, Specification No. C-SPP-G-00101, July 26,2000

[3] Li, W., Mega-Trench Geotechnical Data (U), PEC-SGS-2001-00026, May 15, 2001

[4] Soil Survey of Savannah River Plant Area, Parts of Aiken, Barnwell, and Allendale Counties, South Carolina, a Publication of the National Cooperative Soil Survey, completed in 1987

[5] Chaker, V and Palmer, J. David, "Effects of Soil Characteristics on Corrosion", ASTM, STP 1013, 1989

[6] Romanoff, M, Underground Corrosion, National Bureau of Standards Circular 579, April 1, 1957

[7] Vessel, E. M., Corrosion of Underground Steel Piping - Evaluation of SRS Conditions (U), SRT-MTS-945128, August 19, 1994.

[8] Jones, W. E., Long-Term Waste Stabilization Parameter Estimation, Savannah River Site, Aiken, South Carolina (U), WSRC-TR-2001-00323, September, 2001

[9] Yau, W. W. F, Structural Responses of B-25 Containers to Burial Ground Operation (U)", DPST-86-335, March 14, 1986

[10] McMullin, S. R., Evaluation of Dynamic Compaction of Low Level Waste Burial Trenches Containing B-25 Boxes (U)”, WSRC-RP-94-737, September 1994 
[11] Fontana, M. G., "The Eight Forms of Corrosion", p. 1-39, Process Industries Corrosion, NACE, Houston TX, 1975

[12] Florian Mansfeld, “Corrosion Mechanisms”, Marcel Dekker, Inc., New York, 1987 


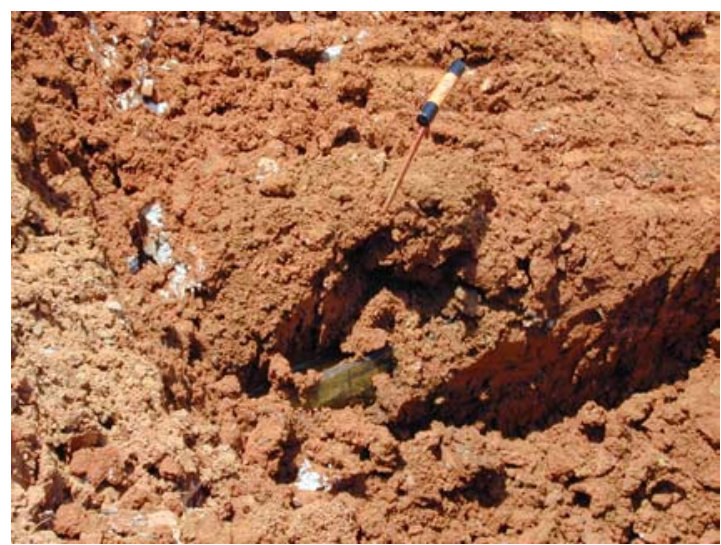

(a)

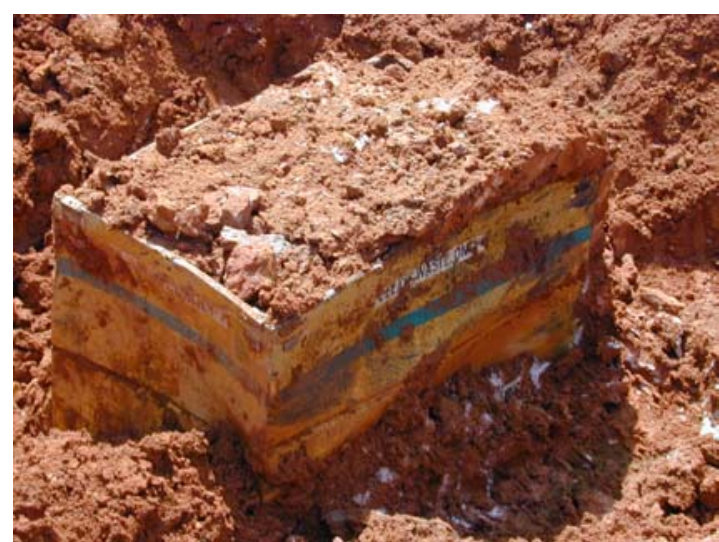

(b)

Figure 1 B-25 at dig site (a) B-25 just uncovered (b) exterior of B-25 exposed.

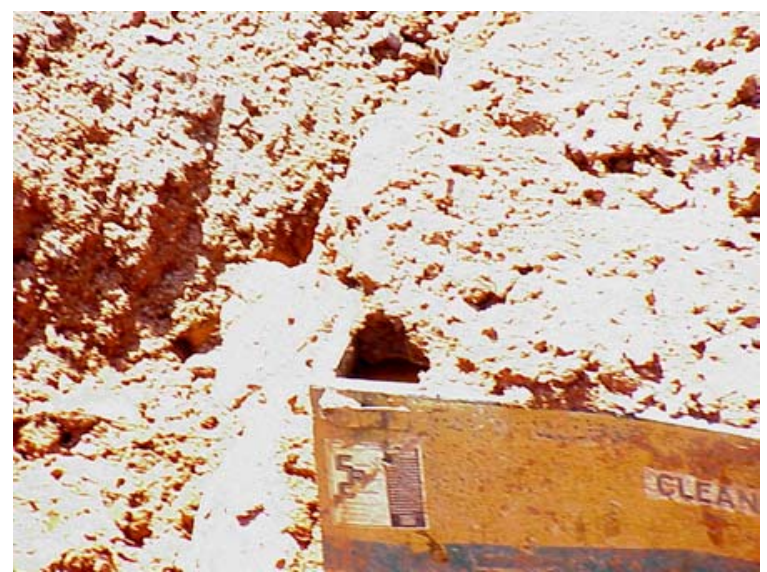

(a)

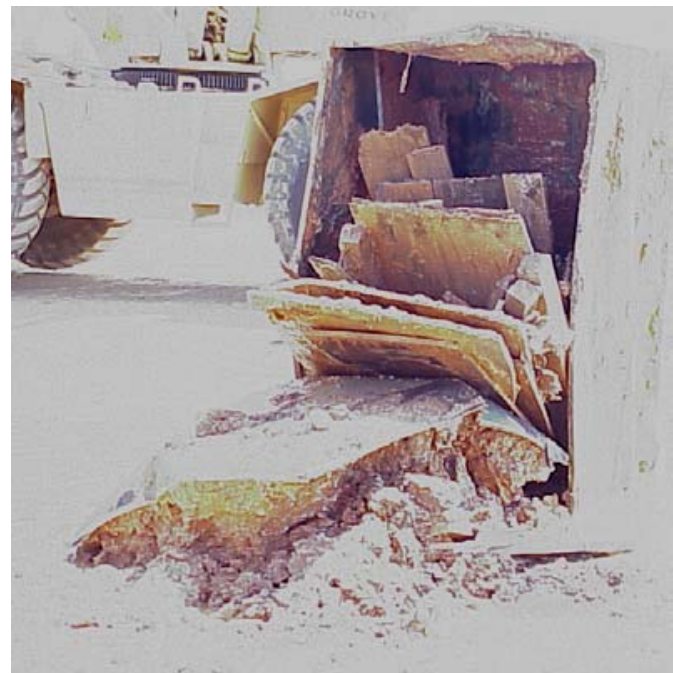

(b)

Figure 2 B-25 at dig site showing presence of water and soil inside box (a) Opening into B25 container (b) Water and soil dumped out of B-25 container. 


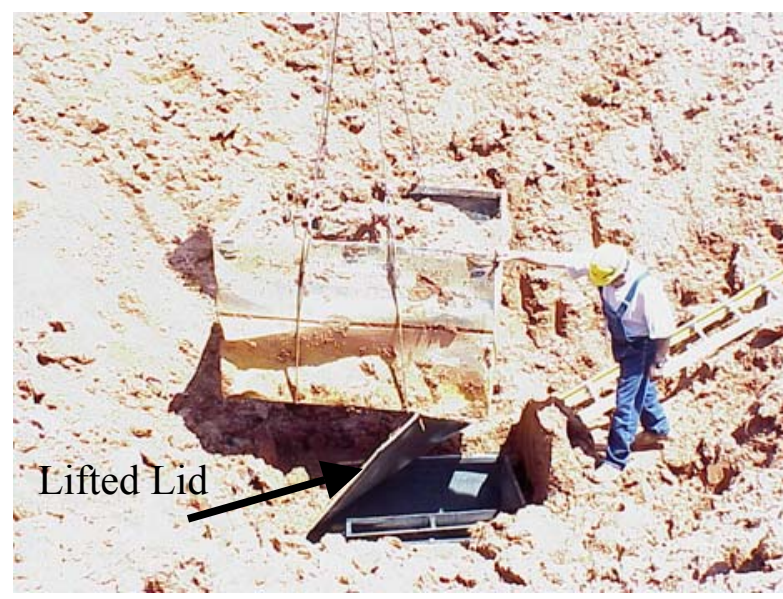

(a)

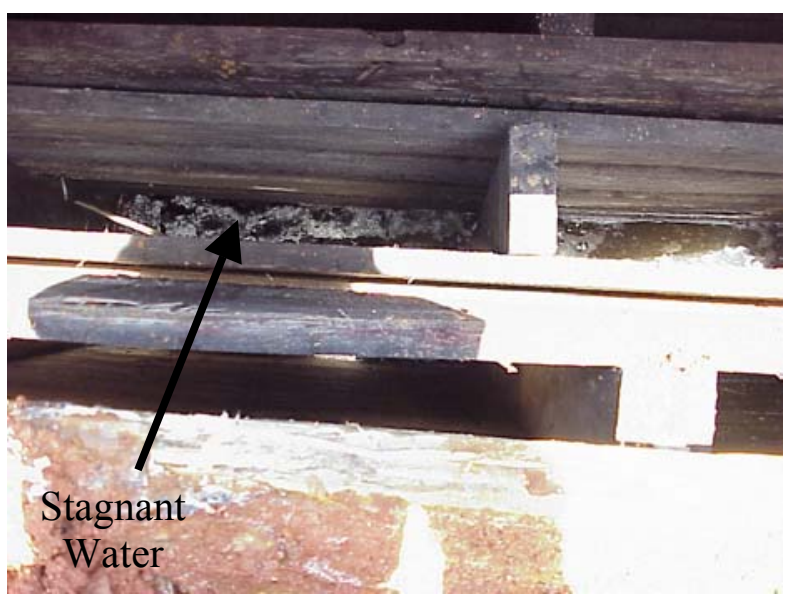

(b)

Figure 3 Buried B-25 below the excavated B-25. Lid was intact yet water was present inside the container (a) Lower lid lifted off B-25 container (b) Stagnant water in bottom of B-25 container.
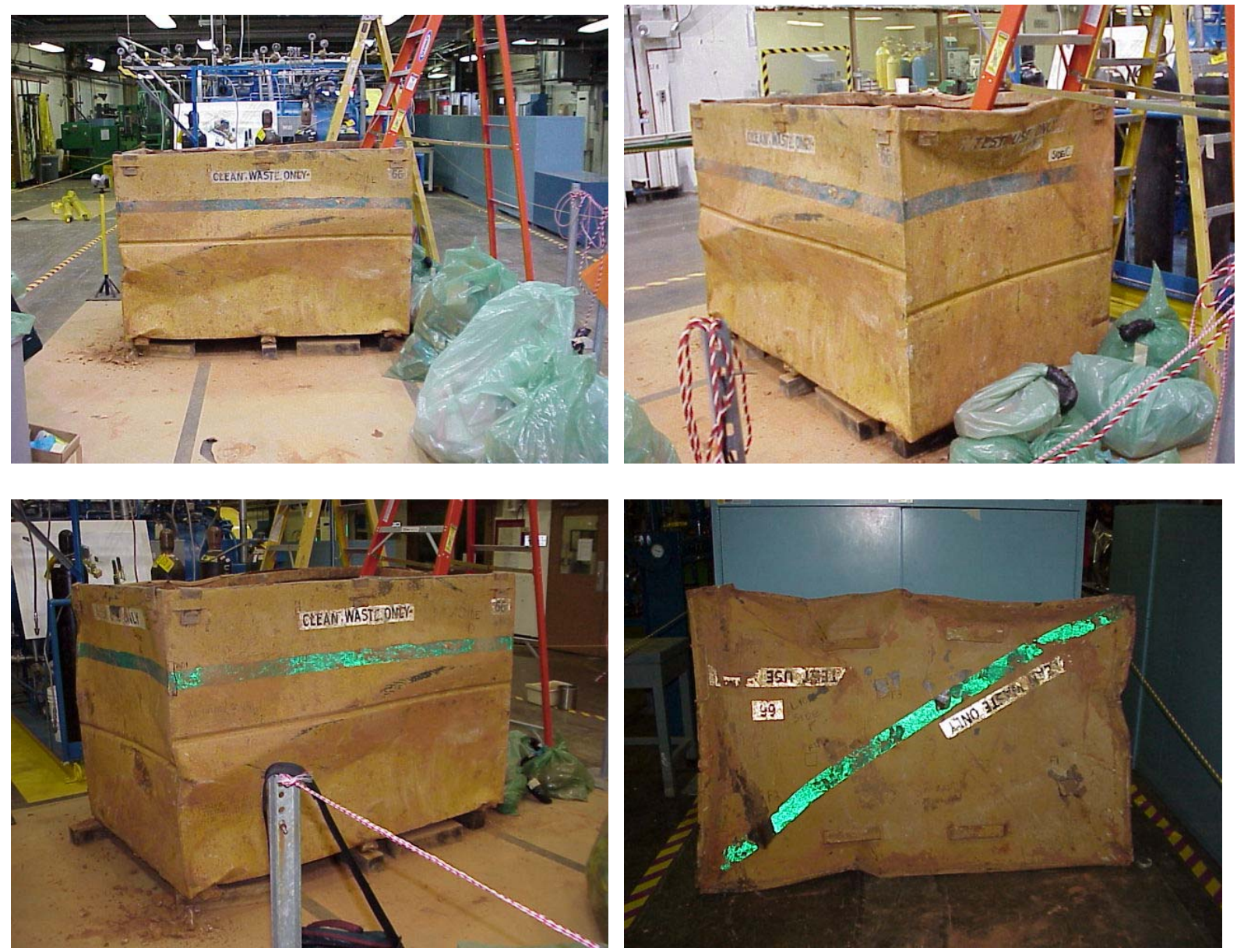

Figure 4 Outside of excavated B-25. No visible corrosion (rust) seen. 

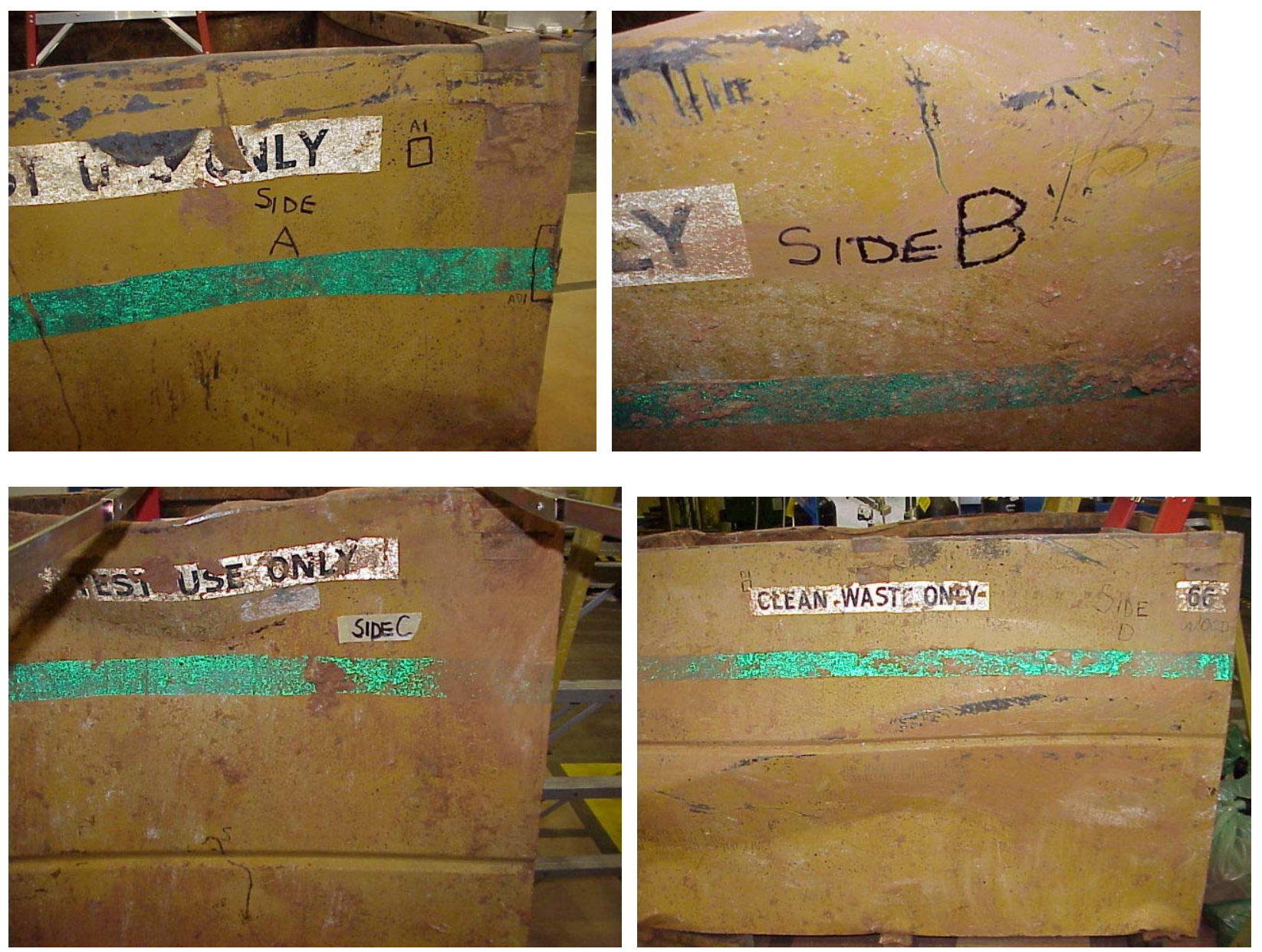

Figure 5 Excavated B-25 showing primer and alkyd enamel intact over much of the container. Lack of enamel on several areas due to handling (forklift, etc.). 
WSRC-TR-2001-00587

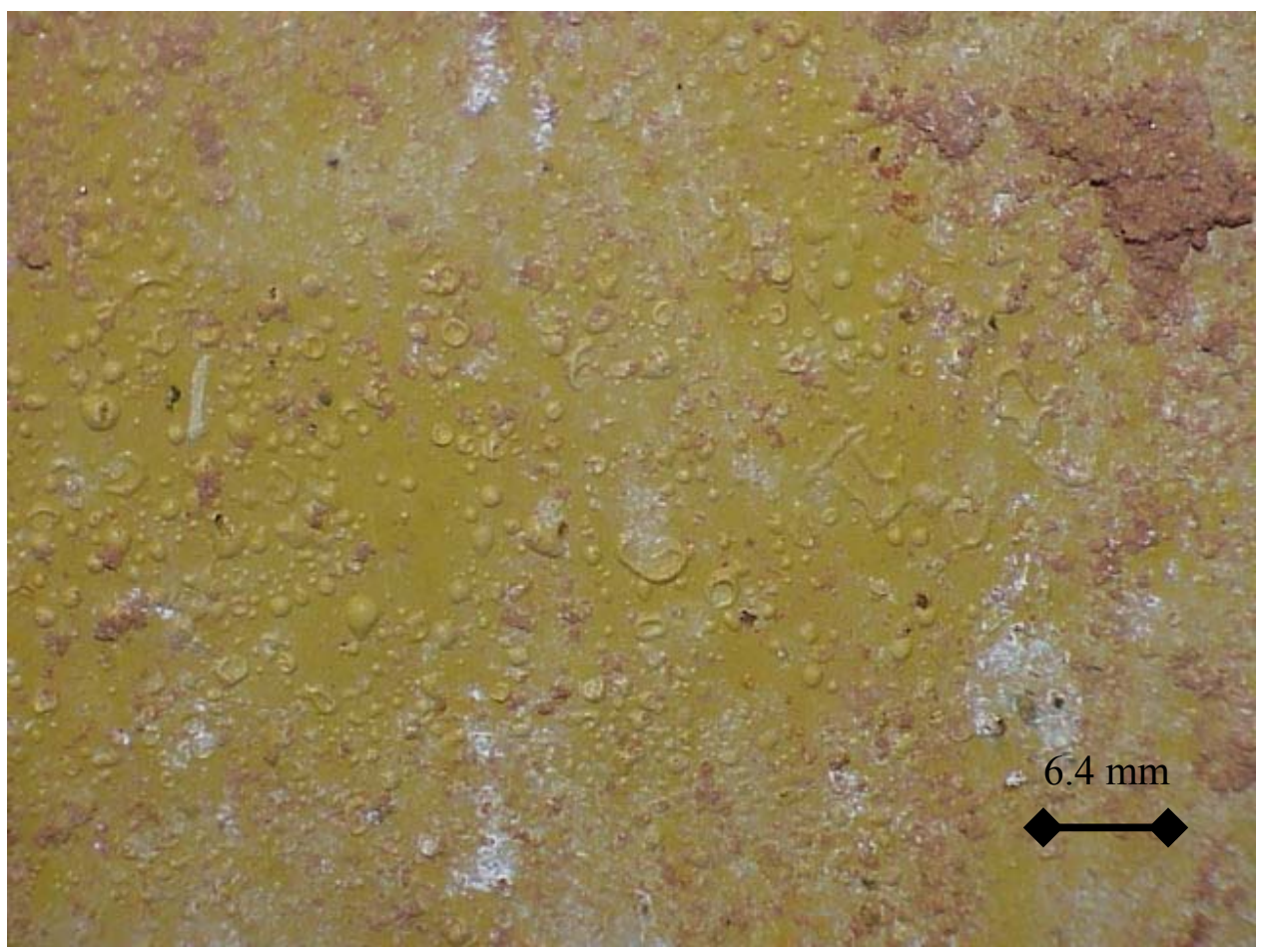

Figure 6 Alkyd enamel blistering over much of the B-25 container surface. 

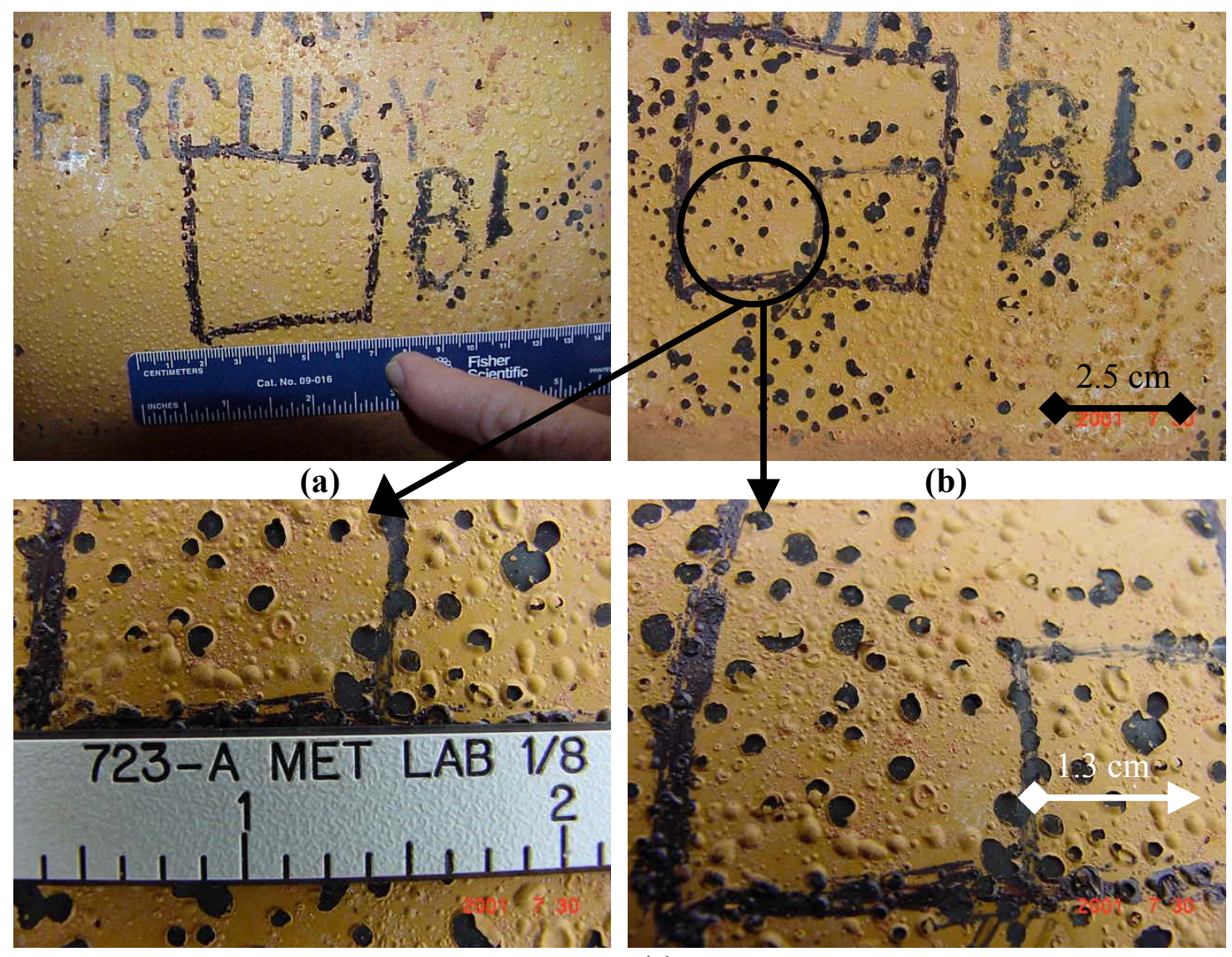

(b)

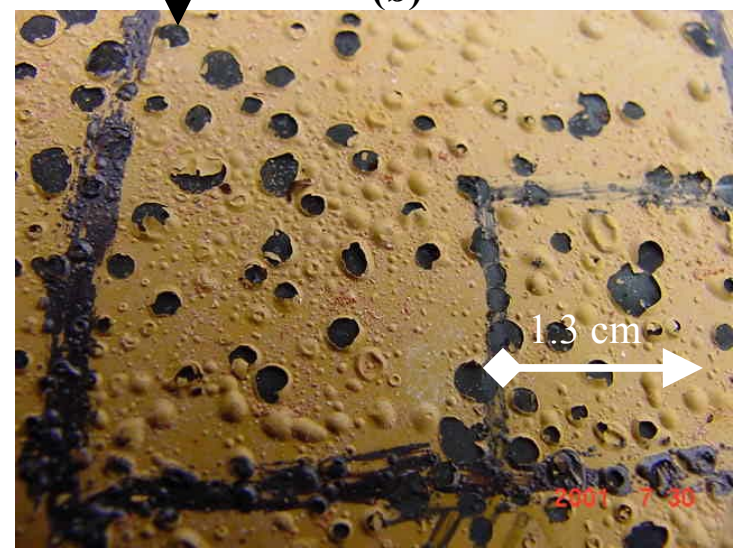

(c)

Figure 7 Paint blisters on the surface of B-25 container (a) Intact blisters, (b) broken blisters, (c) broken blisters showing intact primer.

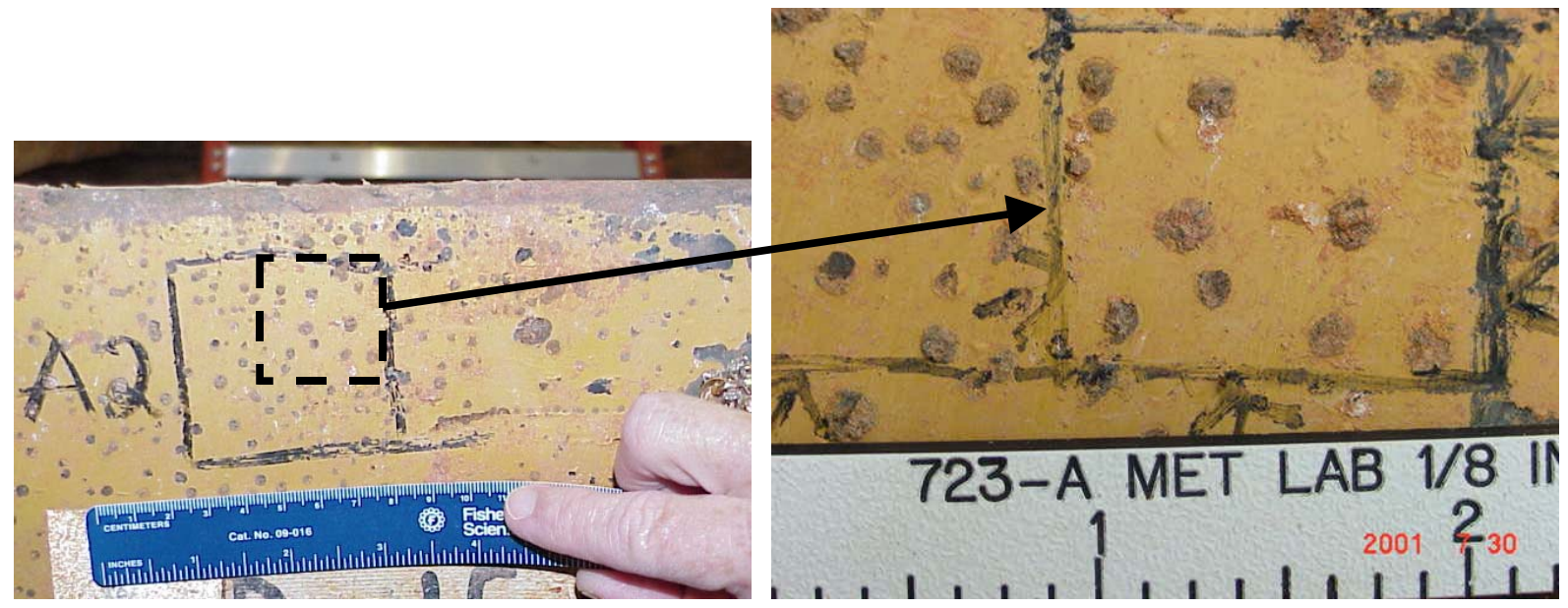

Figure 8 Pitted area with corrosion build-up on surface. 
WSRC-TR-2001-00587

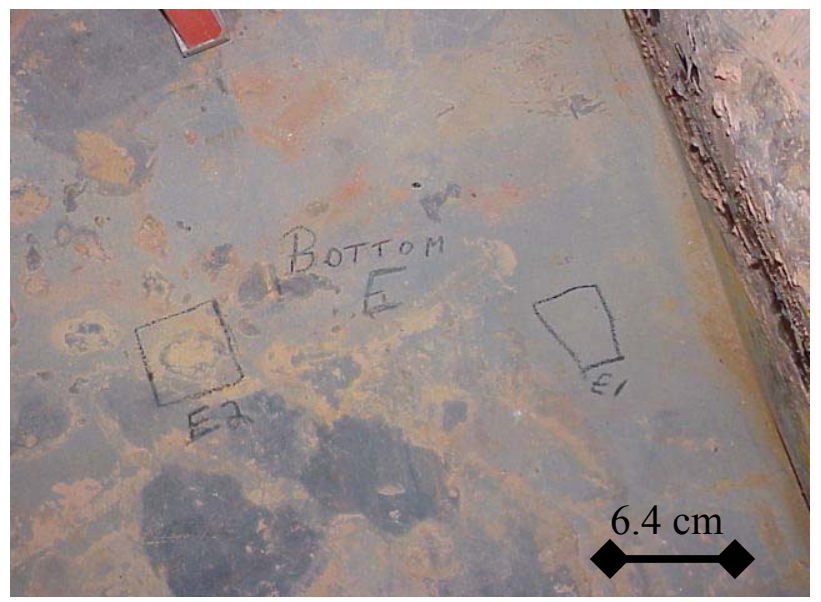

(a)

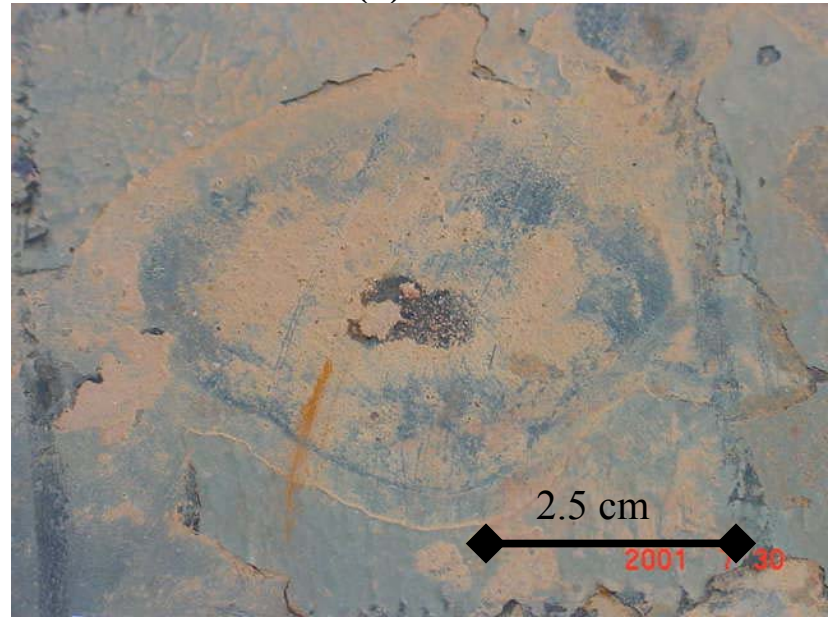

(c)

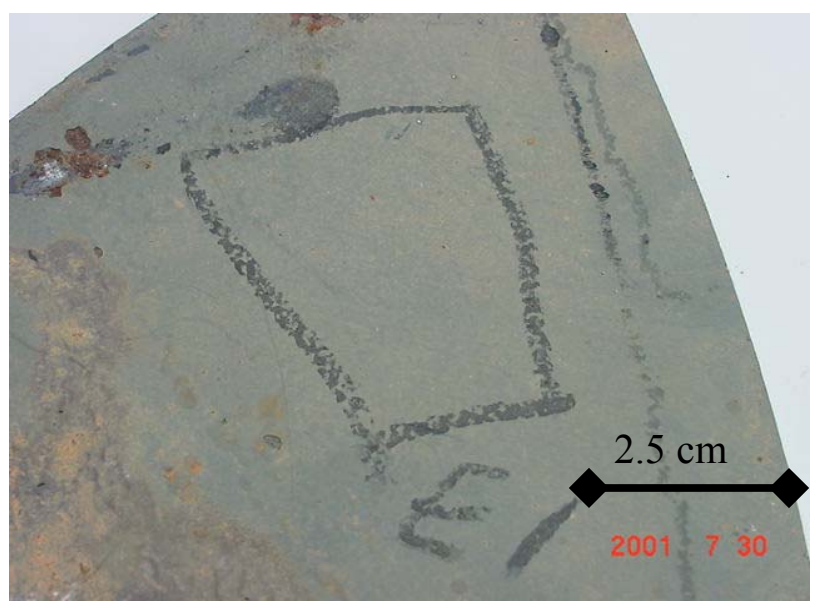

(b)

Figure 9 Inside bottom of B-25 container (a) No corrosion (rust) is visible, (b) Primer appears to be adhered to some of the surfaces, (c) Primer has flaked off surface and degradation is visible. 


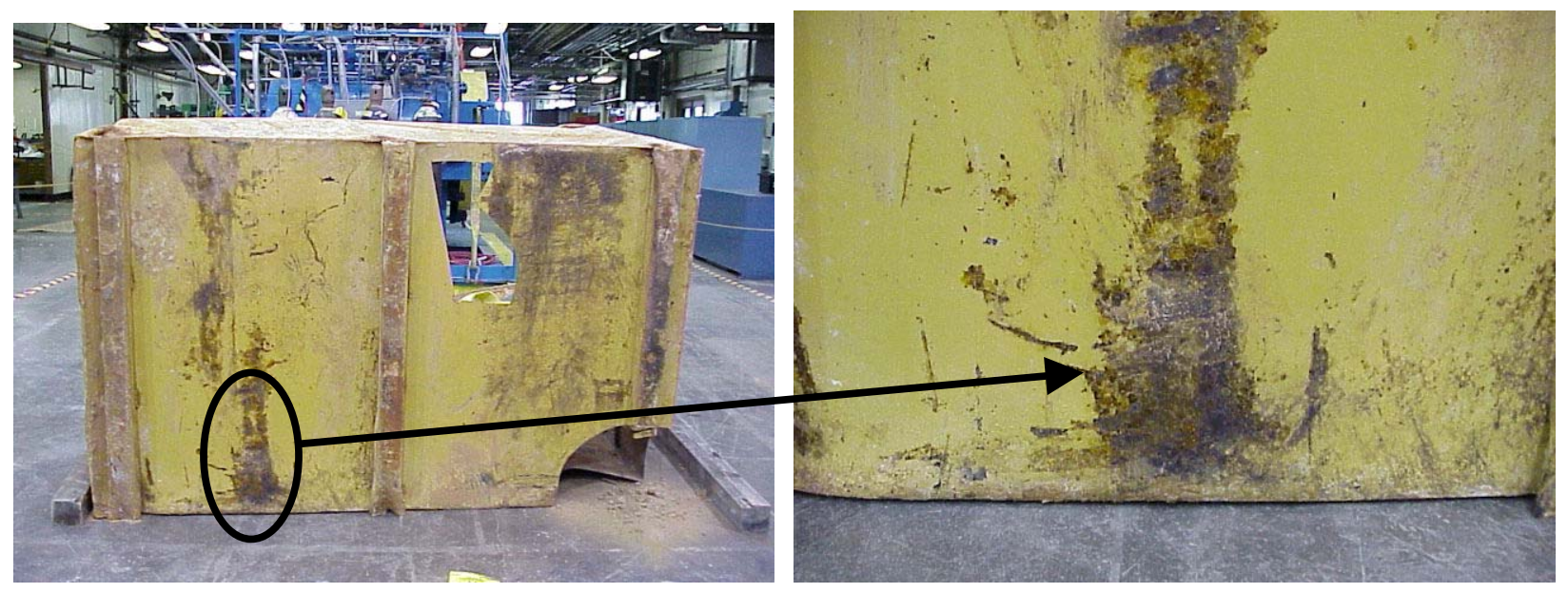

Figure 10 Outside bottom of excavated B-25. Presence of corrosion (rust) as a result of abrasions from a forklift prior to burial.

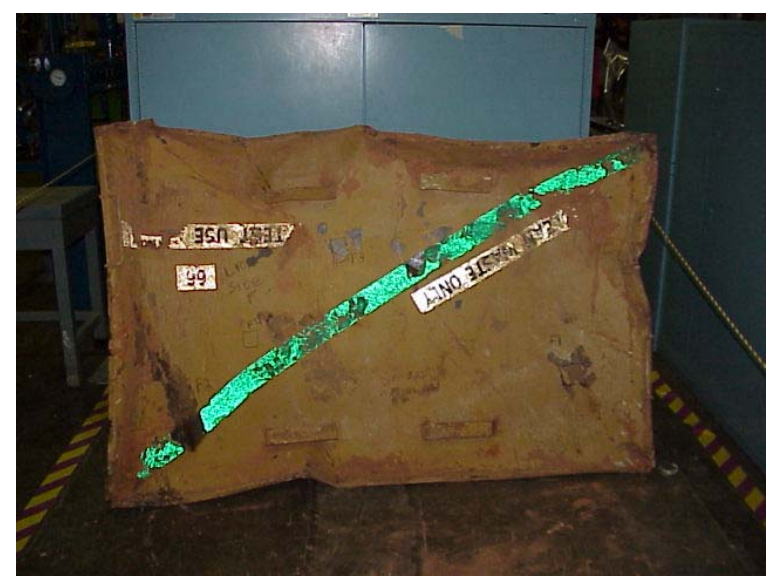

Figure 11 B-25 container lid deformation due to weight of soil during burial process. 
WSRC-TR-2001-00587

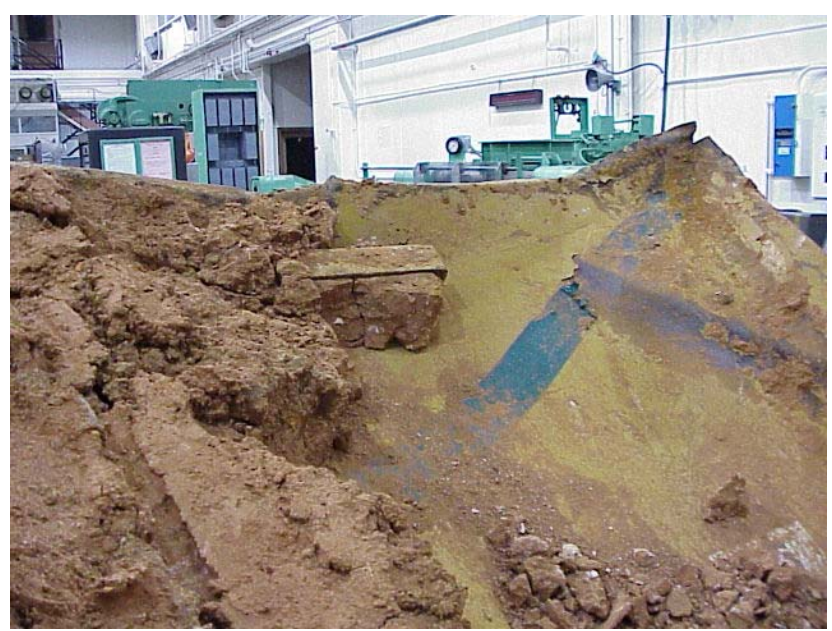

Figure 12 Soil in close contact with B-25 container lid.
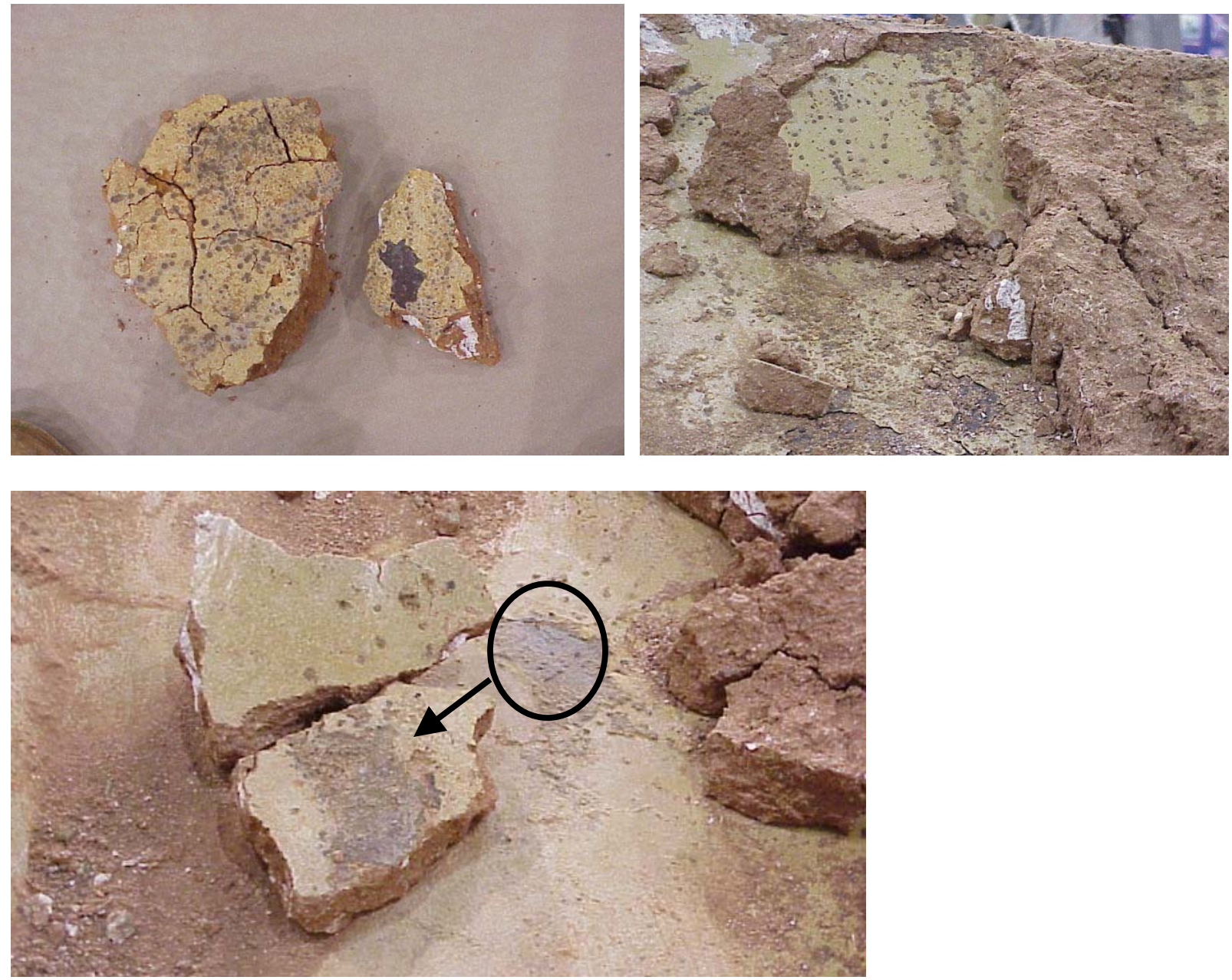

Figure 13 Chunks of soil showing the imprints of pitting on lid surface. 
WSRC-TR-2001-00587
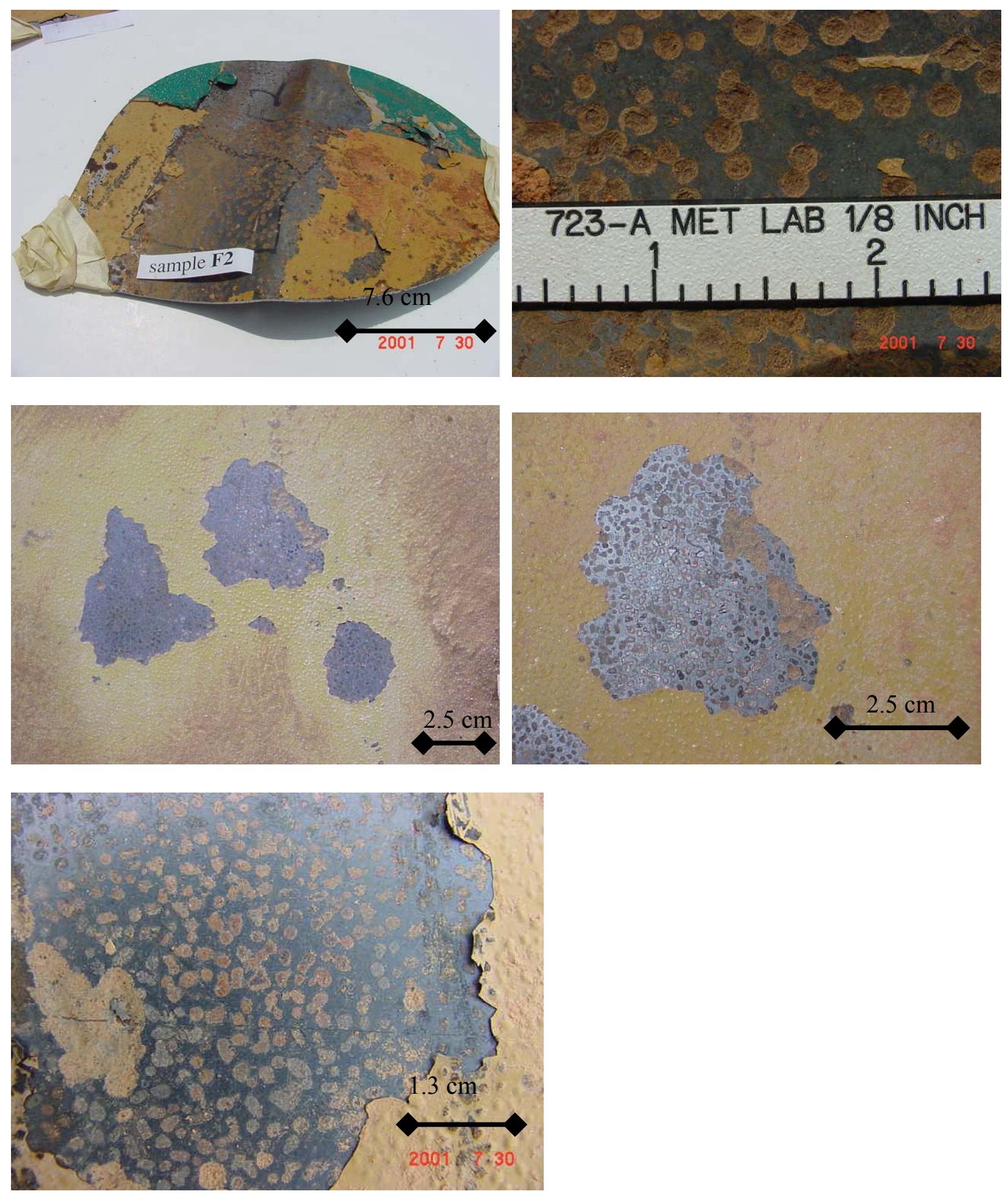

Figure 14 Large areas of macroscopic pitting on lid surface. 

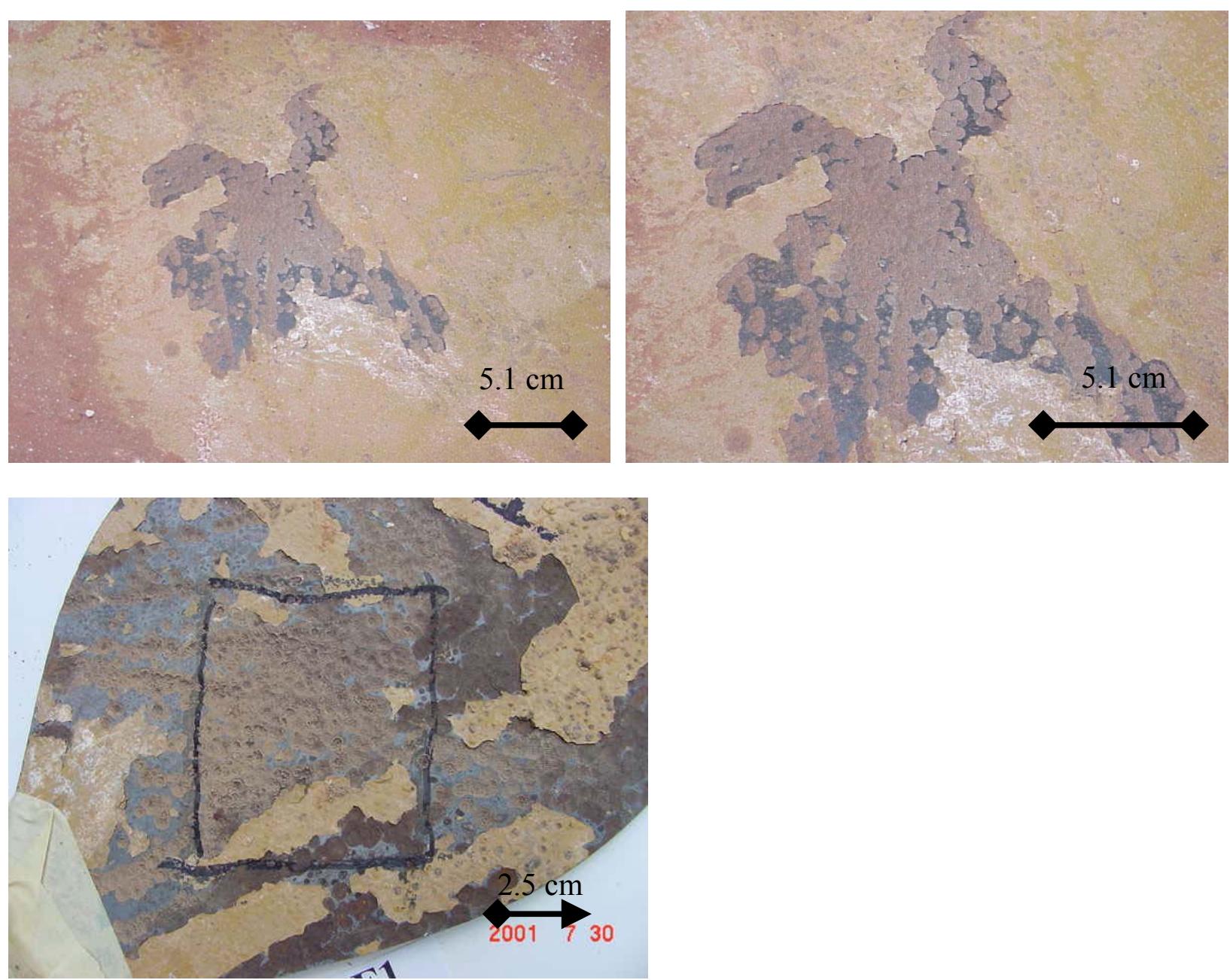

Figure 15 Coalesced pitting on lid surface.
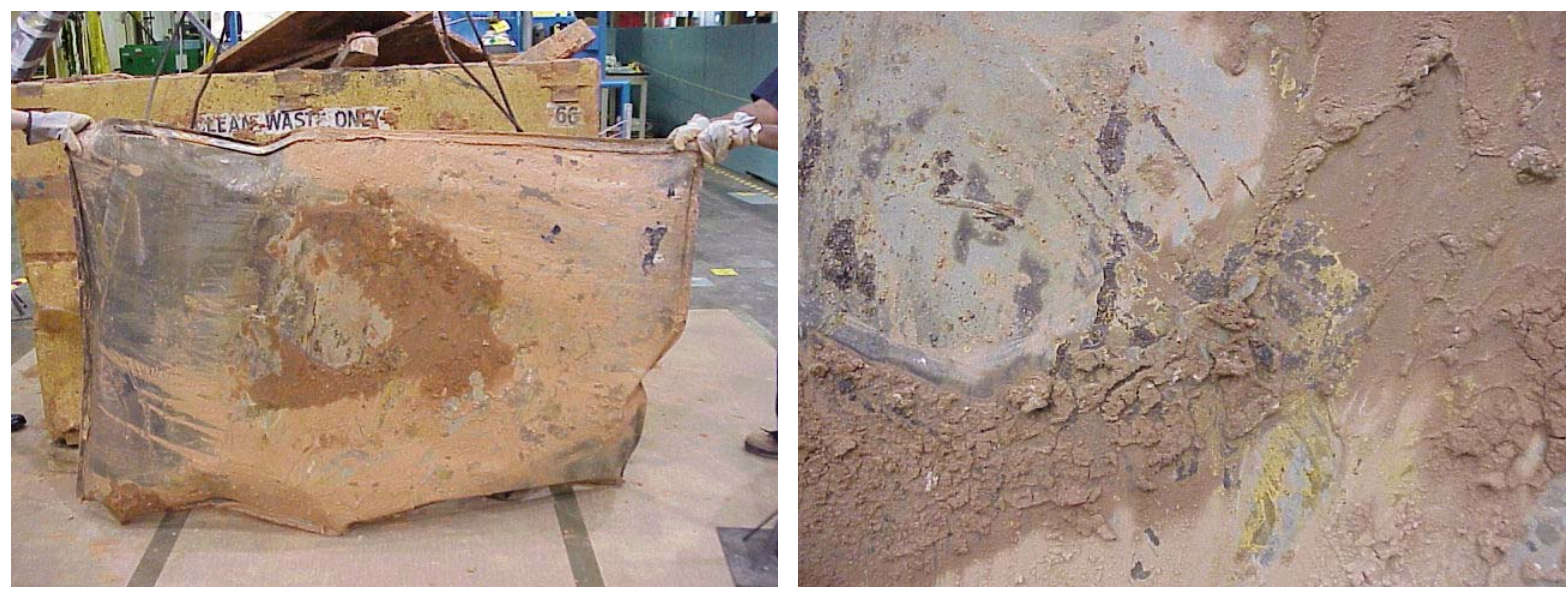

Figure 16 Underside of B-25 container lid showing primer delamination. 
WSRC-TR-2001-00587

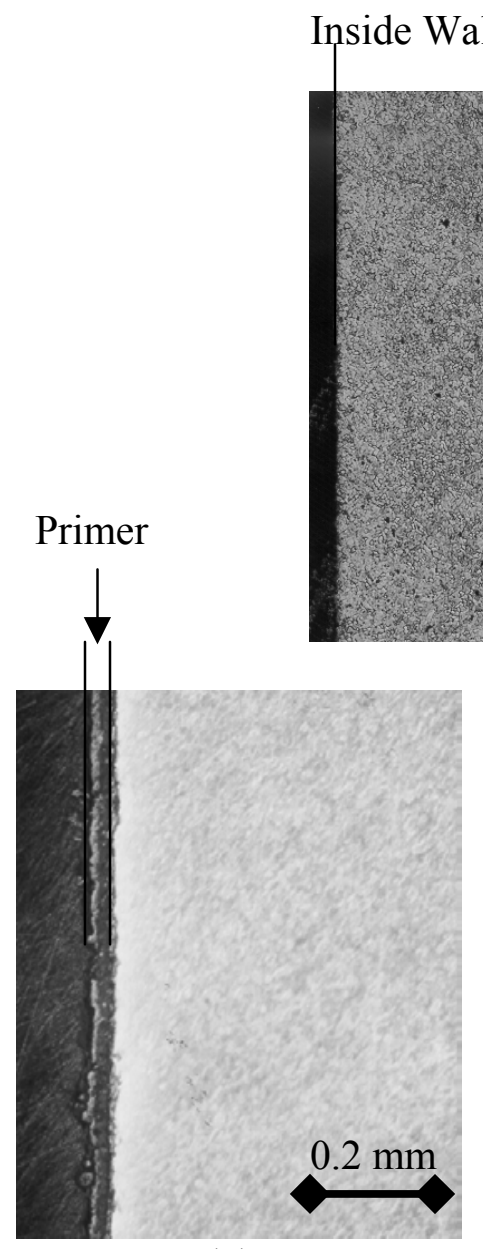

(b)

(a)

Outside Wall

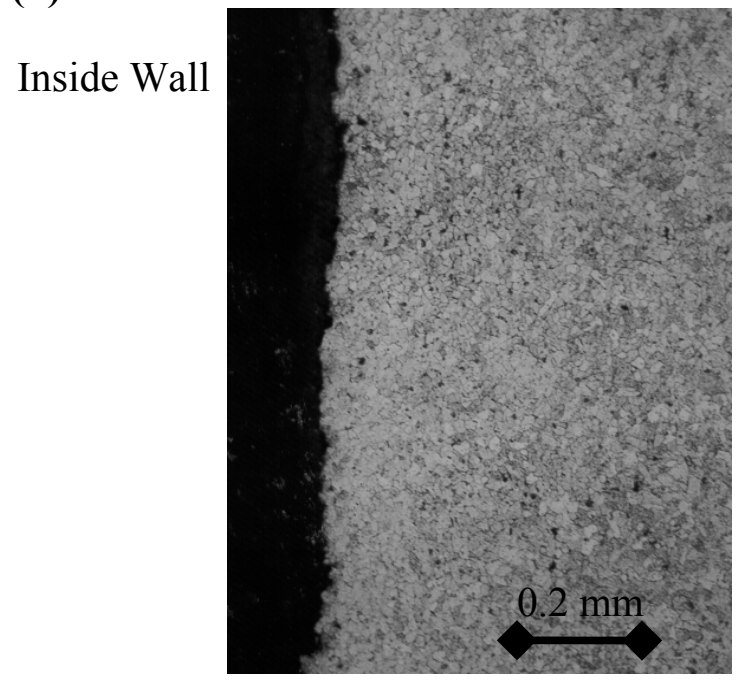

(c)

(d)

Figure 17 Metallographic cross section of B-25 wall in an area with good primer and enamel adhesion (a) Nominal wall thickness, (b) Primer thickness, (c) Alkyd enamel thickness, (d) Little to no degradation in B-25 wall. 


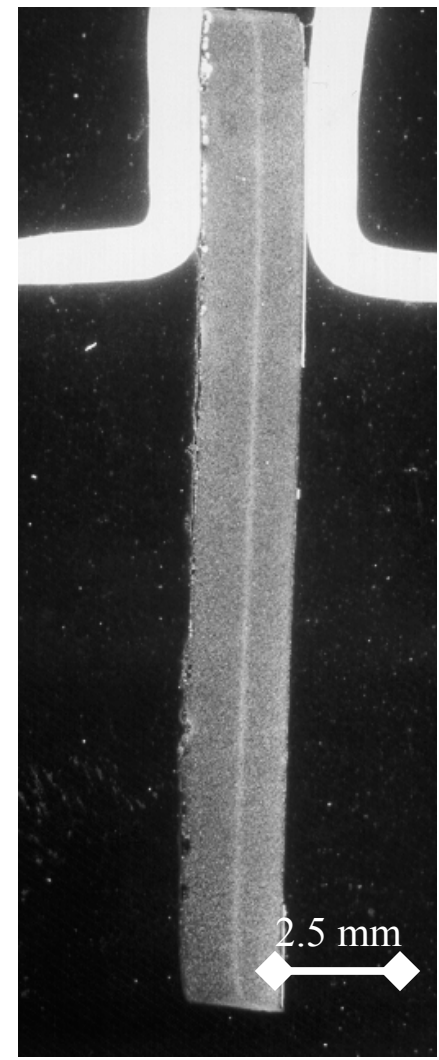

(a)

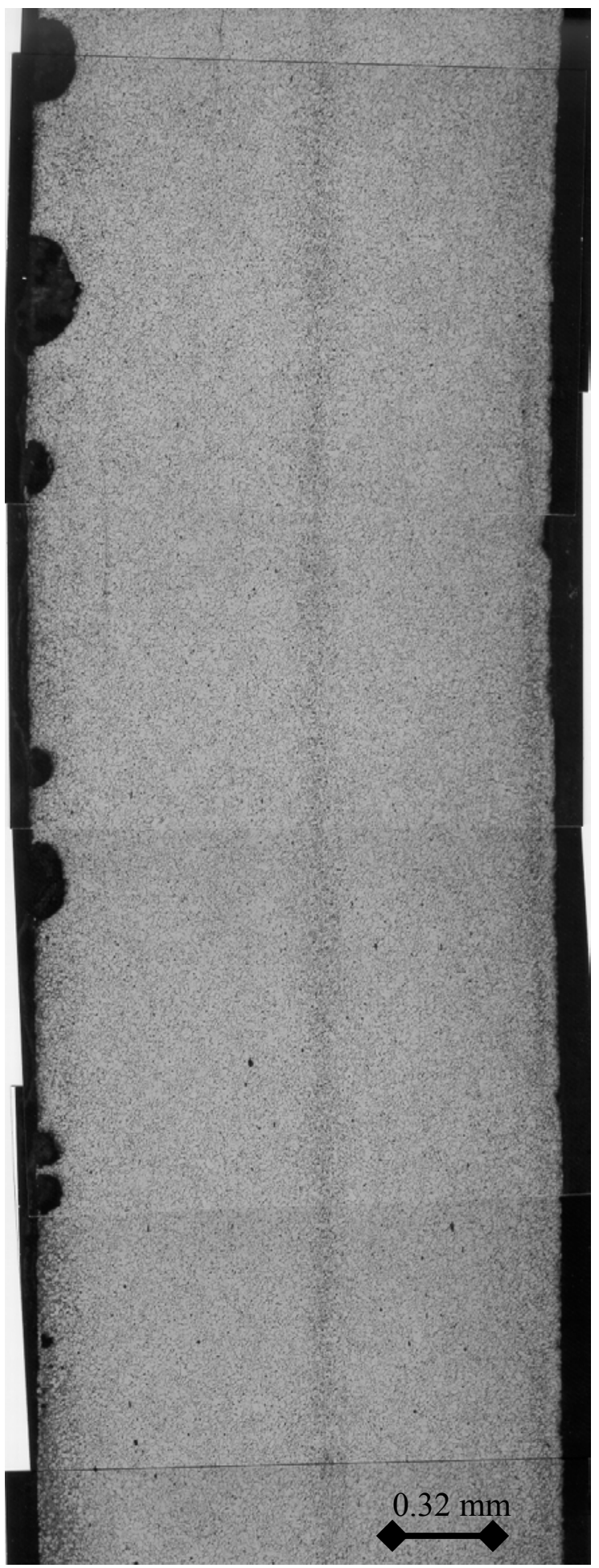

(b)

Figure 18 Metallographic cross section at B1 (Reference Figure 7) from a blistered enamel area on exterior of B-25 container. Note the inside pitting rather than the outside (a) Low magnification of overall sample, (b) Montage of region. 


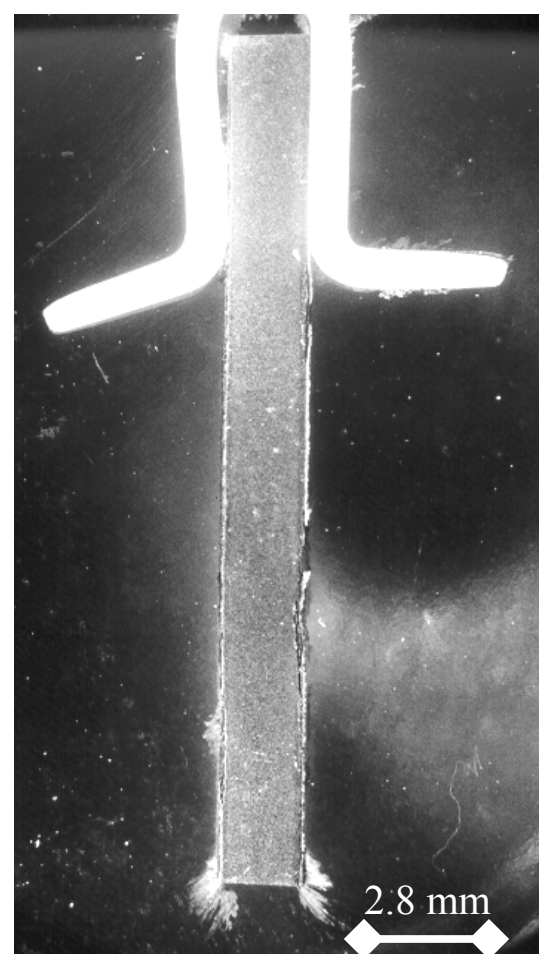

(a)

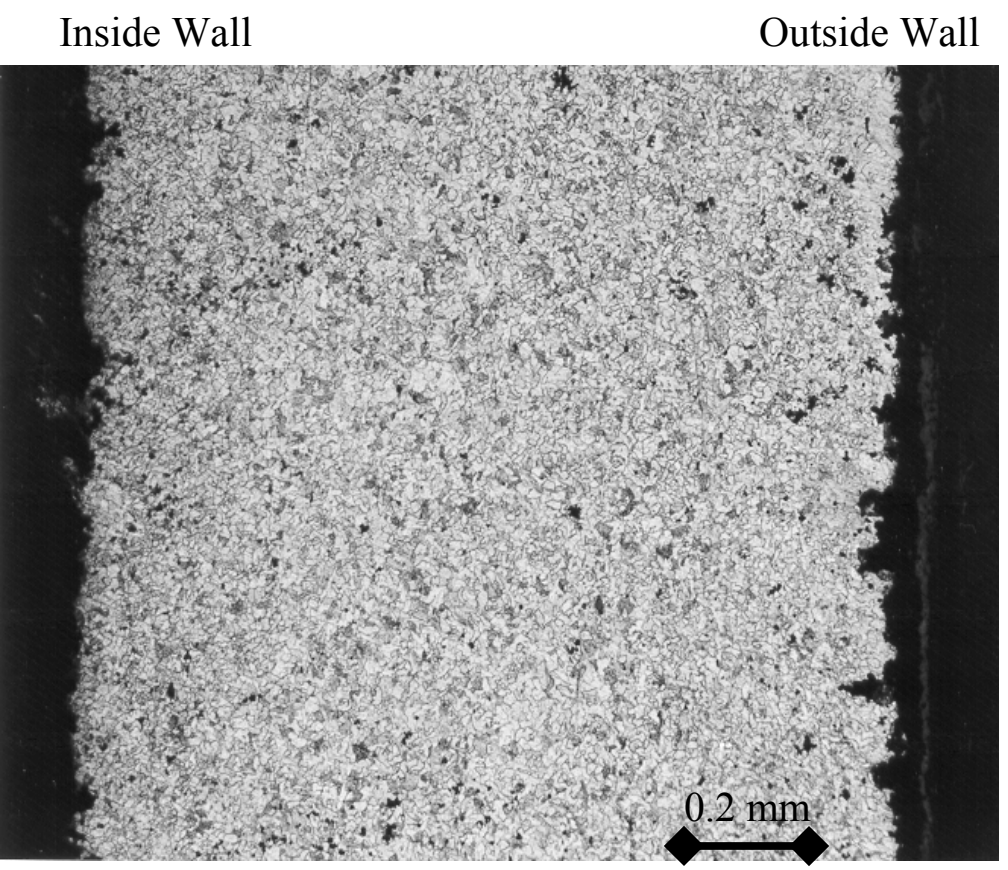

(b)

Figure 19 Metallographic crossection of area where blisters had flaked off of exterior of container (a) Low magnification of overall sample, (b) Higher magnification of pitting on both inside and outside of wall. 


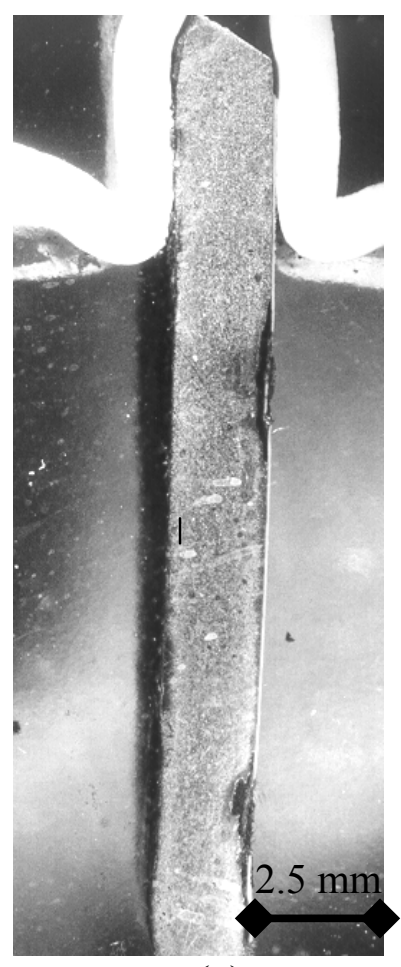

(a)
Inside Wall

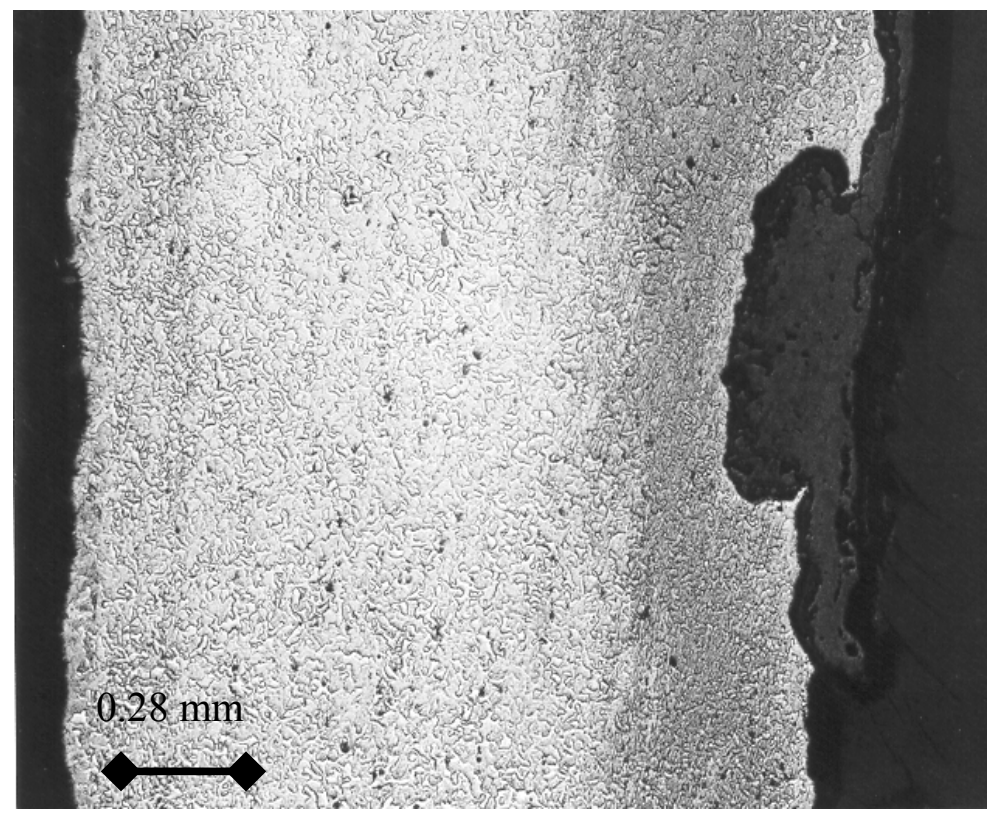

(b)

Figure 20 Metallographic cross section showing pits where oxide layer formed on exterior wall of B-25 (Reference Figure 8) (a) Low magnification of overall sample, (b) Higher magnification of deep pits from outside to inside. Some general corrosion seen from inside to outside. 


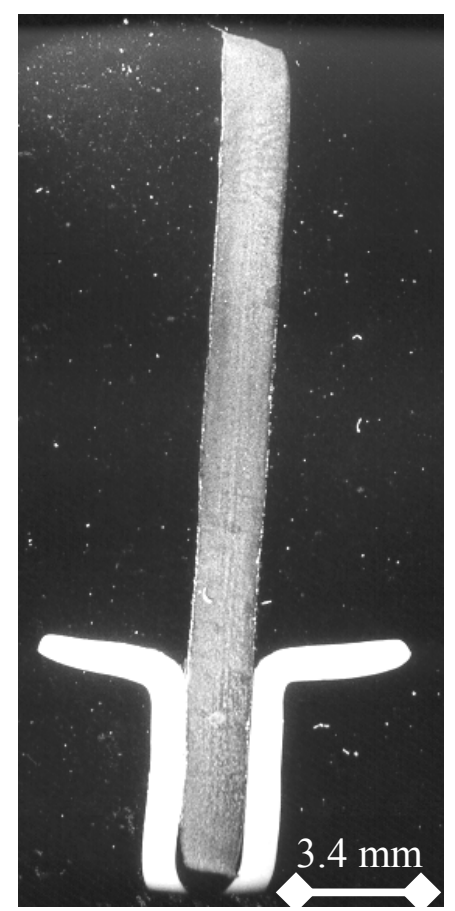

(a)
Inside Wall Outside Wall

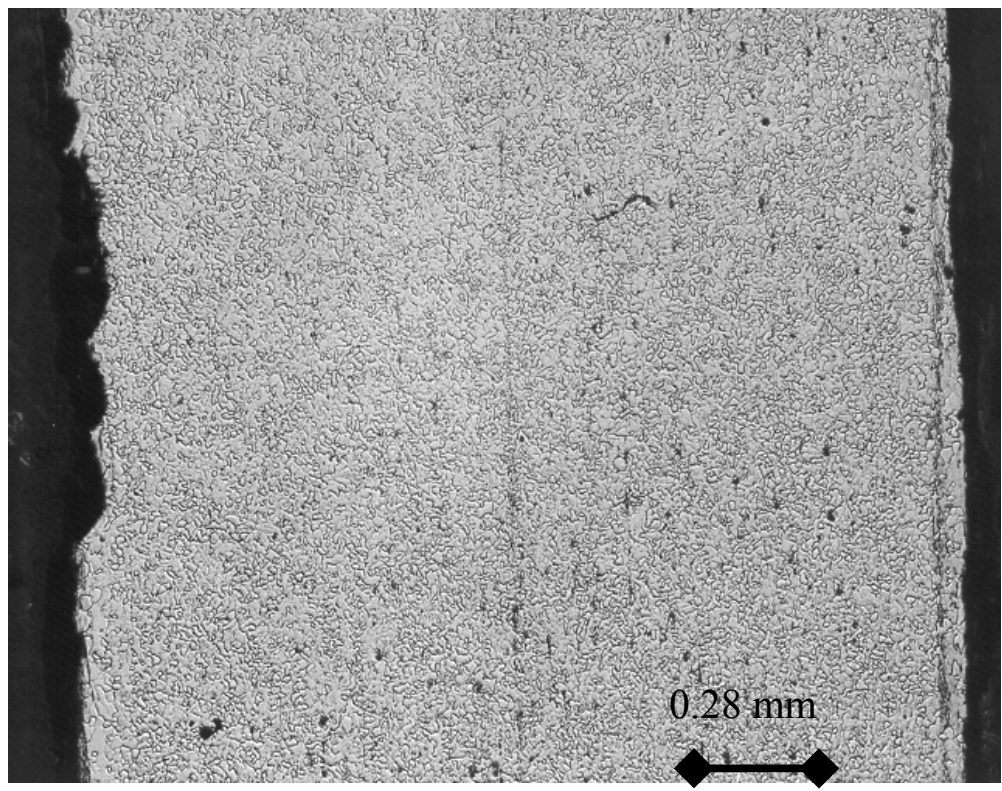

(b)

Figure 21 Metallographic cross section of B-25 container floor showing the delamination of the inside primer (Reference Figure 9) (a) Low magnification of overall sample, (b) Higher magnification showing no primer and general corrosion of wall. 


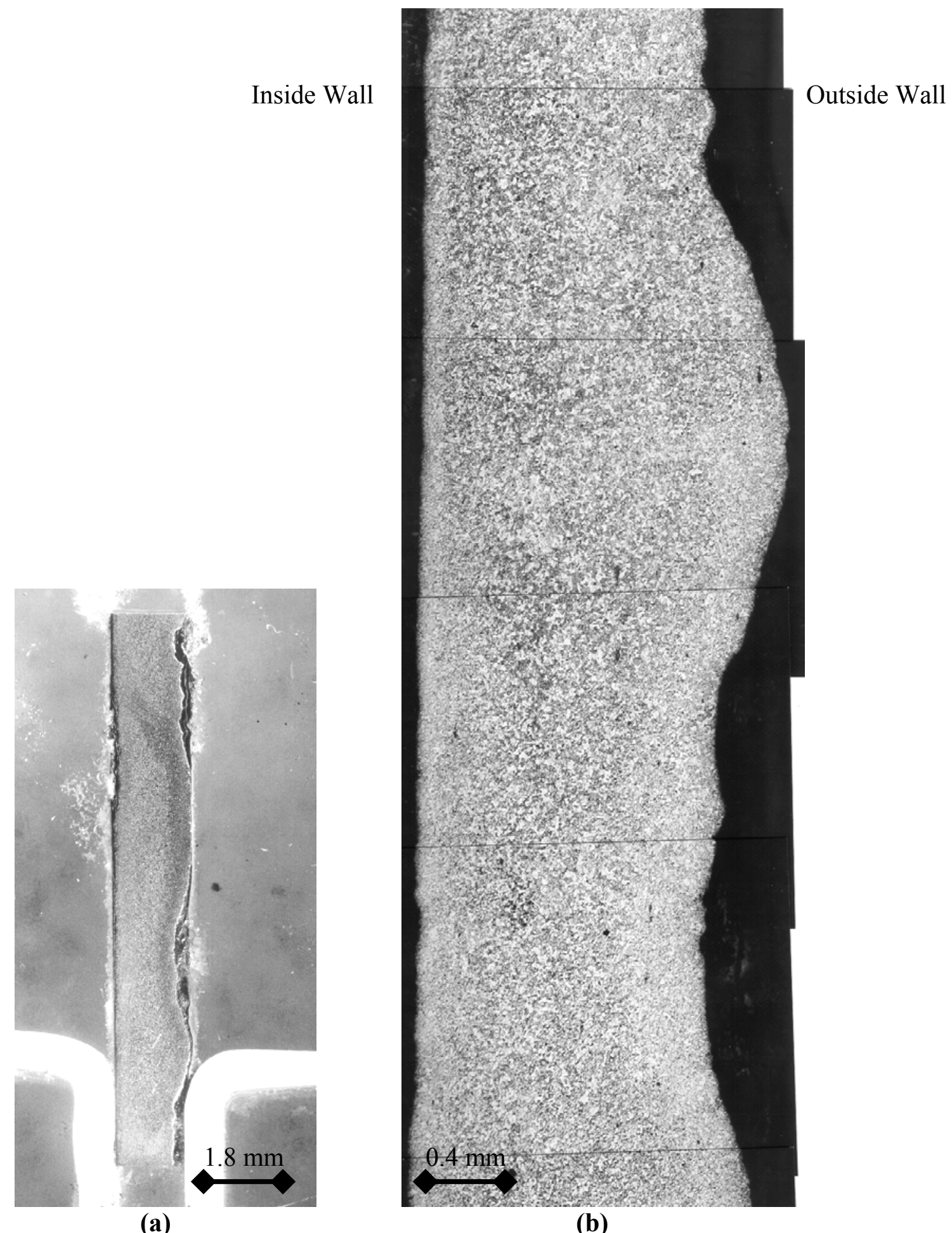

Figure 22 Metallographic cross section of B-25 container floor showing the presence of general corrosion on the outside section due to abrasions from a forklift prior to burial (Figure 10) (a) Low magnification of overall sample, (b) Higher magnification montage showing level of corrosion degradation to the floor. 

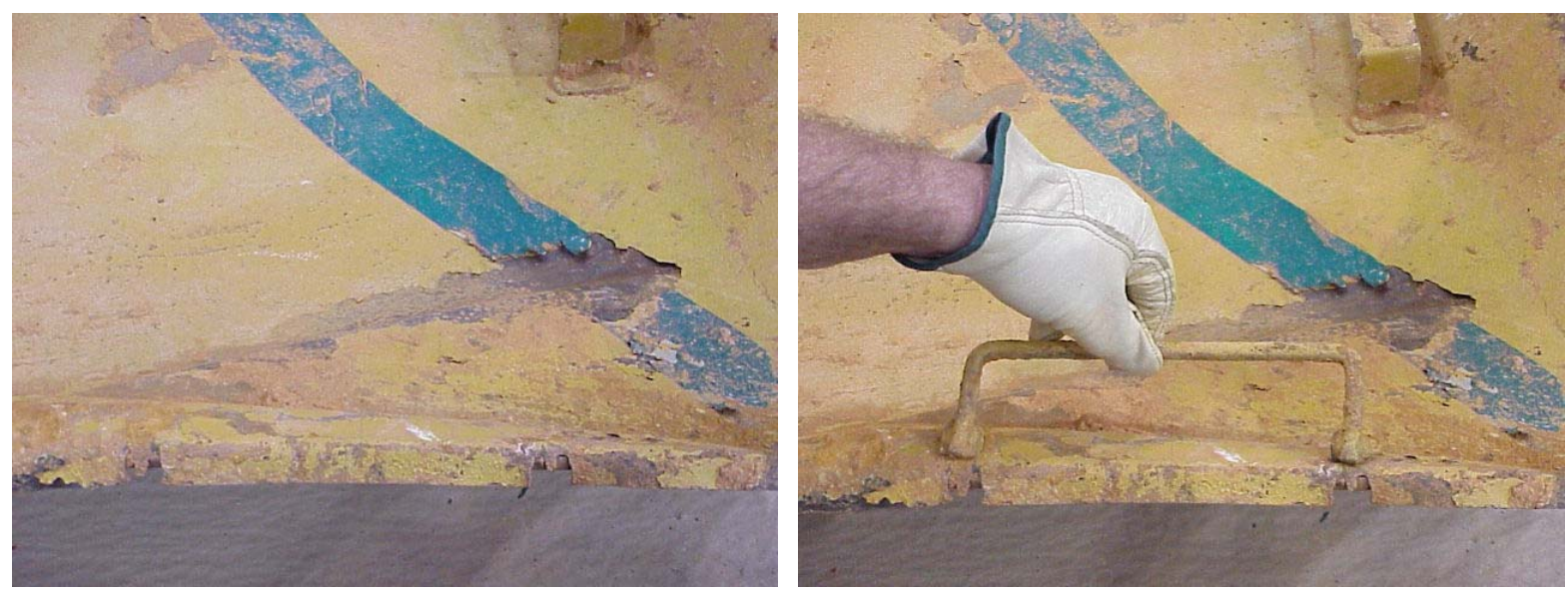

Figure 23 Lid handle found dismantled from B-25 container.

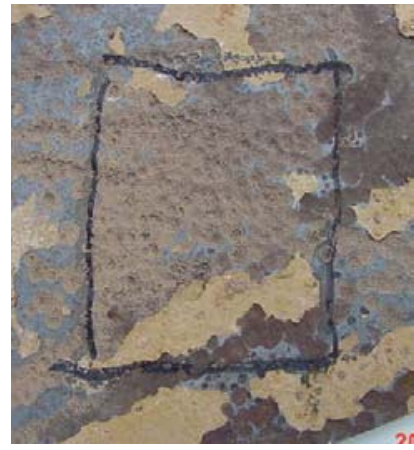

(a)

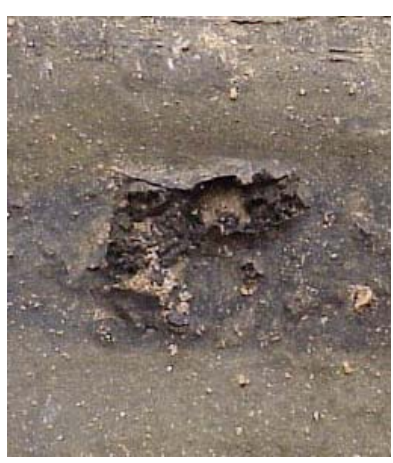

(b)

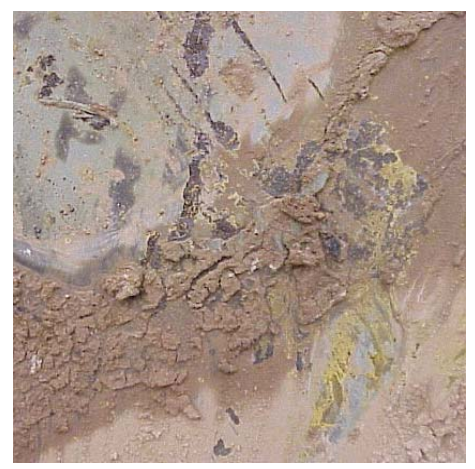

(c)

Figure 24 Corrosion on inside and outside of lid. Paint and/or primer has delaminated from the surface where soil was in close contact with metal. (a) Outside of lid, (b) Inside of lid, (c) Inside of lid. 


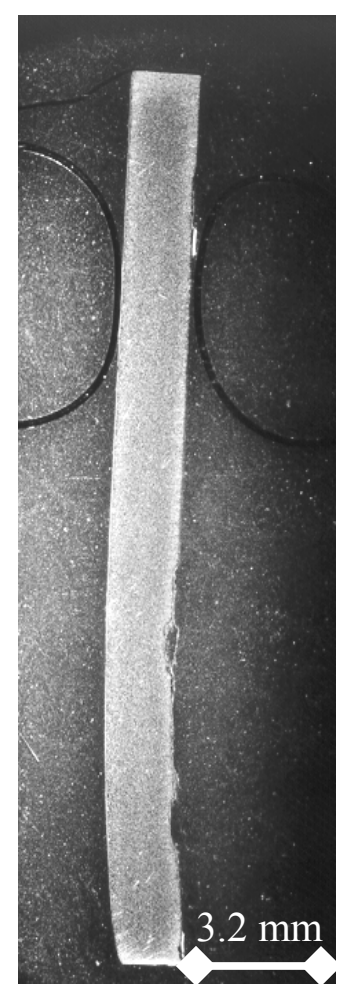
Inside Wall
Outside Wall
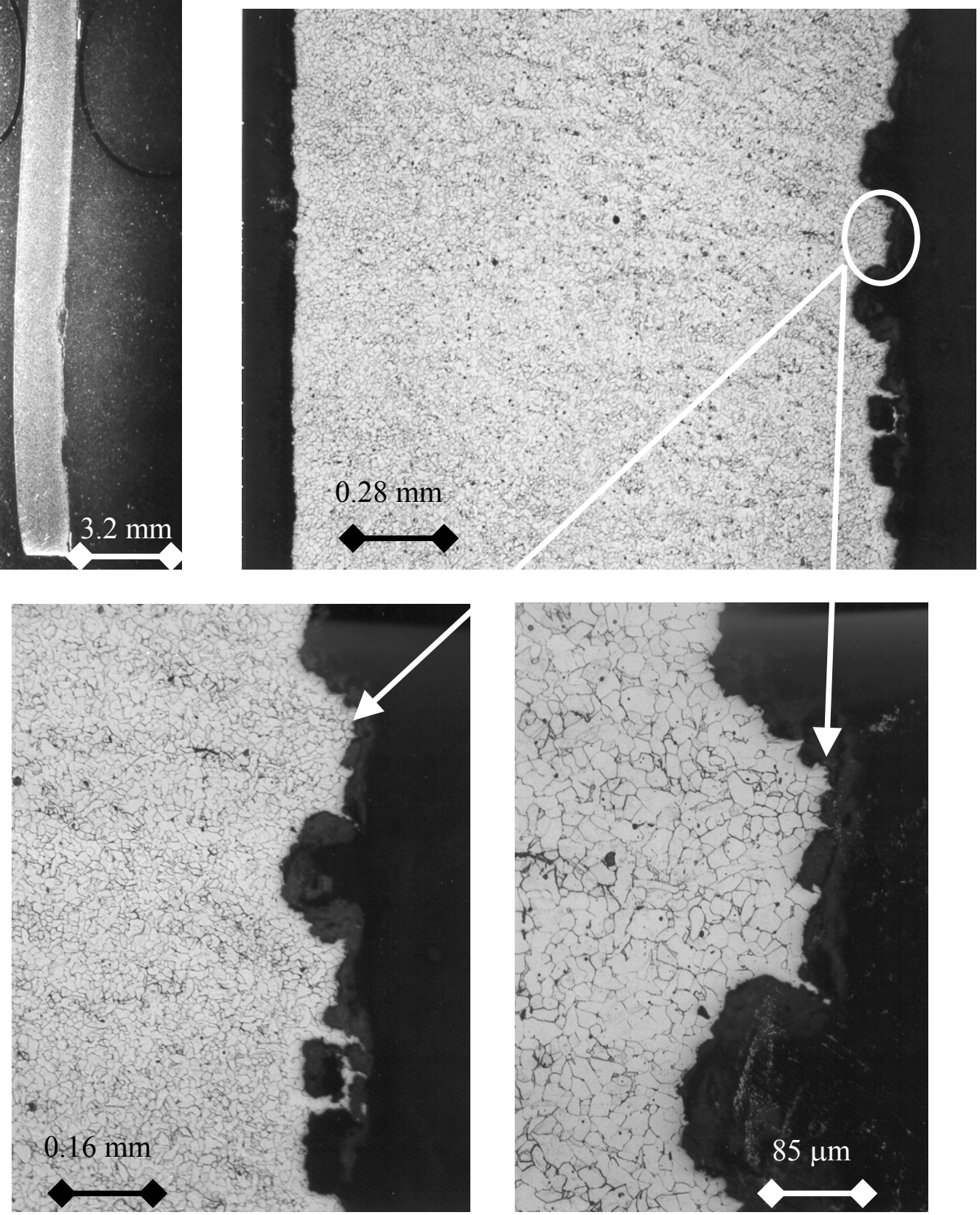

Figure 25 Metallographic cross section of lid showing wide shallow pits (Reference Figure 14). 
WSRC-TR-2001-00587
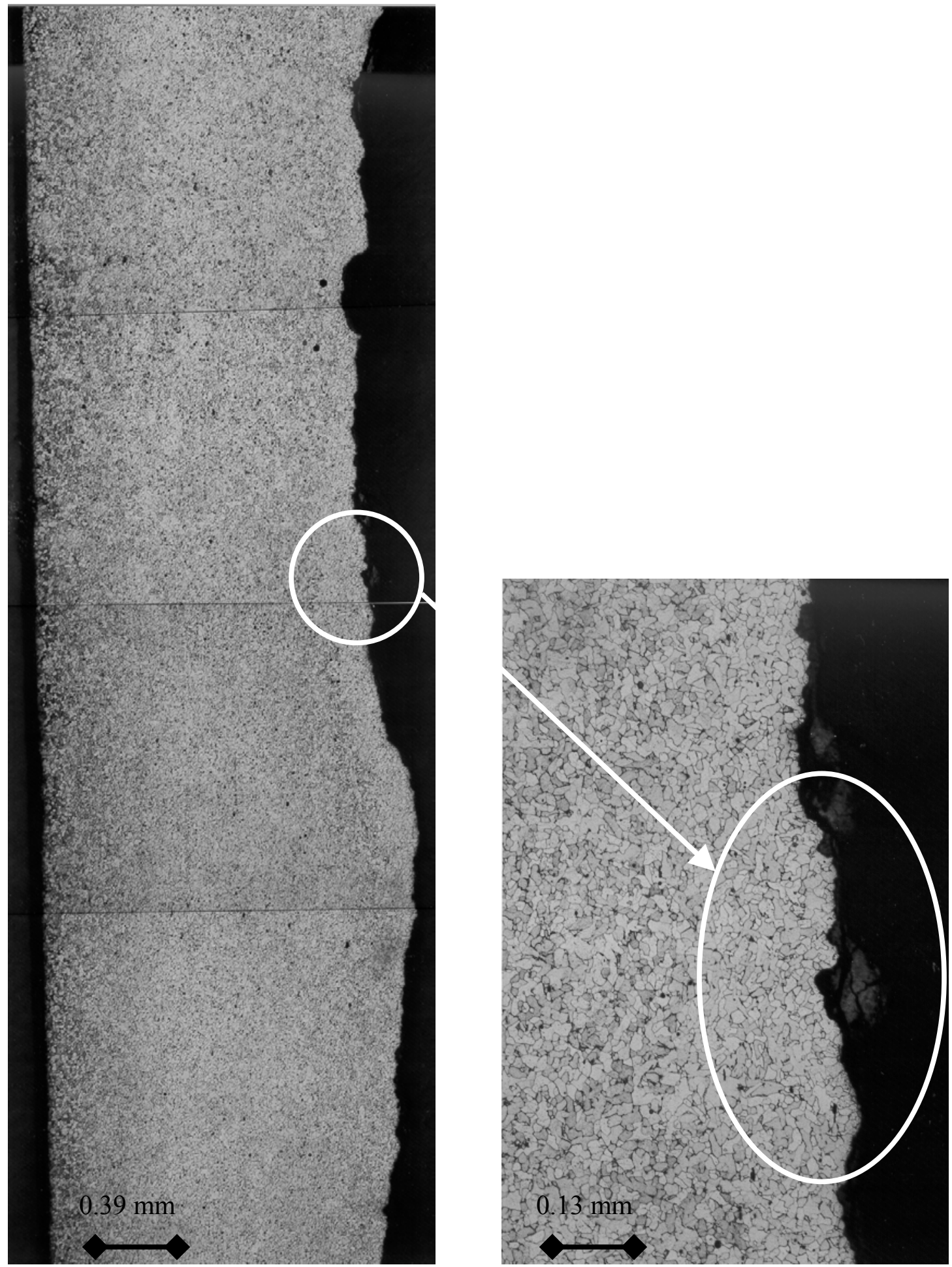

Figure 26 Metallographic cross section showing region on lid of B-25 container with coalesced pits (Reference Figure 15). 
CC:

G. T. Chandler, 773-A

K. J. Imrich, 773-A

N. C. Iyer, 773-41 A

C. F. Jenkins, 730-A

M. R. Louthan, Jr., 773-41A

E. J. Majzlik, Jr., 773-A

J. I. Mickalonis, 773-A

M. A. Phifer, 773-42A

M. G. Serrato, 773-42A

R. L. Sindelar, 773-41A

B. J. Wiersma, 773-A

P. E. Zapp, 773-A

Document Control, 773-51A 